IZA DP No. 6661

Power of the Pill or Power of Abortion?

Re-Examining the Effects of Young Women's

Access to Reproductive Control

Caitlin Knowles Myers

June 2012 


\title{
Power of the Pill or Power of Abortion? Re-Examining the Effects of Young Women's Access to Reproductive Control
}

\author{
Caitlin Knowles Myers \\ Middlebury College \\ and IZA
}

\section{Discussion Paper No. 6661}

June 2012

IZA
P.O. Box 7240
53072 Bonn
Germany

Phone: +49-228-3894-0

Fax: +49-228-3894-180

E-mail: iza@iza.org

\begin{abstract}
Any opinions expressed here are those of the author(s) and not those of IZA. Research published in this series may include views on policy, but the institute itself takes no institutional policy positions.

The Institute for the Study of Labor (IZA) in Bonn is a local and virtual international research center and a place of communication between science, politics and business. IZA is an independent nonprofit organization supported by Deutsche Post Foundation. The center is associated with the University of Bonn and offers a stimulating research environment through its international network, workshops and conferences, data service, project support, research visits and doctoral program. IZA engages in (i) original and internationally competitive research in all fields of labor economics, (ii) development of policy concepts, and (iii) dissemination of research results and concepts to the interested public.
\end{abstract}

IZA Discussion Papers often represent preliminary work and are circulated to encourage discussion. Citation of such a paper should account for its provisional character. A revised version may be available directly from the author. 


\section{ABSTRACT \\ Power of the Pill or Power of Abortion? Re-Examining the Effects of Young Women's Access to Reproductive Control ${ }^{*}$}

Recent research postulating that the diffusion of confidential access to the birth control pill to young women in the United States contributed to the dramatic social changes of the late 1960 s and 1970s has not adequately accounted for the largely contemporaneous diffusion of access to abortion. Estimates using a new panel of data on state policies related to access to the pill and abortion indicate that while access to the pill may have played a role in the sexual revolution, it had little effect on the probabilities of entering into marriage and parenthood at a young age. In contrast, both the legalization of abortion and the enactment of laws permitting young unmarried women to consent to it led to substantial delays in marriage and motherhood.

JEL Classification: I18, J12, J13

Keywords: abortion, contraception, fertility, marriage

Corresponding author:

Caitlin Knowles Myers

Department of Economics

Middlebury College

Middlebury, VT 05753

USA

E-mail: cmyers@middlebury.edu

\footnotetext{
*I wish to thank IZA for a stimulating and productive sabbatical visit. I also thank Martha Bailey, Jeffrey Carpenter, Erick Gong, Melanie Guldi, Christiane Hellmanzik, Heinrich Hock, Jessica Holmes, Theodore Joyce, Lawrence Katz, Peter Matthews, Casey Rothschild, Travis Warziniack, and participants at the 2012 annual meetings of the Society of Labor Economists for helpful comments and suggestions. Madeline Niemi provided research assistance.
} 


\section{Introduction}

The oral contraceptive pill, or simply "the pill," was introduced in 1960 at the inception of two decades of profound social and economic change characterized by sexual revolution, delayed marital formation, reduced fertility, and increased gender equality in the labor force. Some have credited these transitions to the pill, hailing it as "the most important scientific advance of the twentieth century," (The Economist, 1999) and "the pill that changed the world" (Asbell, 1995). Others note that the pill could be a consequence of this change rather than a cause (Becker, 1981). The pill may have arrived at the moment of epochal change, either by result or simple chance, and proved a "handy explanation" (Gibbs, 2010).

Researchers seeking to identify any causal effects of the pill on outcomes for young women in the sixties and seventies have relied on a natural experiment arising from state differences in confidential access to the pill for unmarried women under age 21. Goldin and Katz (2002) use a differences-in-differences specification to provide evidence that female college graduates who legally could consent to the pill prior to age 18 married later and were more likely to pursue graduate education. Subsequent work has extended this framework to produce additional evidence on the "power of the pill" in causing reduced fertility (Bailey, 2006, 2009; Ananat and Hungerman, 2008), increased educational attainment (Hock, 2008), increased marital stability (Zuppann, 2012), improved long-run outcomes for children (Ananat and Hungerman, 2008) and increased female labor supply, wages and occupational diversity (Bailey, 2006; Steingrimsdottir, 2010).

In this paper I use data from Current Population Survey (CPS) June fertility supplements to re-examine the effects of the pill on two outcomes examined in the seminal papers in the literature, age at first marriage (Goldin and Katz, 2002) and age at first birth (Bailey, 2006, 2009), through which it is often 
theorized that the pill indirectly affected other outcomes such as educational attainment and labor supply. I provide two innovations on the previous literature. First, as pointed out by Joyce et al. (2010), there is a great deal of variation in the coding of young women's access to the pill in this literature; the coding of access differs for 35 of 51 states and the District of Columbia between Goldin and Katz (2002), Bailey (2006), Guldi (2008) and Hock (2008). I have revised, reconciled, and corrected the codings of these laws after conducting and extensively documenting the results of a new review of the legal environment affecting adults' and minors' access to reproductive control (Myers, 2012).

Second, I provide a more comprehensive treatment of the complex array of laws affecting women's ability to access reproductive control during this period. Goldin and Katz (2002) and Bailey (2006) estimate the effects of young women's ability to consent to the pill after controlling for the legality of abortion. They do not control for the presence of Comstock laws that limited access to the pill for married adult women in some states in the early sixties, implicitly equating environments in which the pill could not be legally dispensed to any women regardless of age with those in which the pill was legally available, but minors could not consent to it. Nor do they control for minors' ability to consent to abortion even though, just as was the case with the pill, unmarried women under the age of majority could not consent to abortion in the early seventies unless a state medical consent law or judicial precedent permitted them to do so. Because the advent of confidential access to abortion often coincided with that to contraception, the effects of the two could have been conflated. In this paper I differentiate between three policy environments for each form of reproductive control: one in which it was not legally available, one in which it was legally available to adult women but young unmarried women did not have confidential access to it, and one in which it was legally available and young unmarried women did have confidential access to it.

The results of this new analysis using revised coding and more complete 
specification of the policy environment indicate that contrary to earlier conclusions about the power of the pill, the introduction of the pill and legal changes that granted young unmarried women capacity to consent to it had little if any effect on the average probabilities of marrying and giving birth at a young age. In contrast, the estimates indicate that access to abortion had substantial effects on the probabilities of entering into marriage and motherhood. The legalization of abortion is estimated to have led to a 2.8 percentage point reduction in the fraction of women giving birth before age 19, and this increases in magnitude to a 5.0 percentage point reduction if state law explicitly granted young unmarried women the capacity to consent to abortion. With respect to marriage, the legalization of abortion is estimated to have led to a 4.1 percentage point reduction in the fraction of women who married prior to age 19, and this increases to a 5.5 percentage point reduction if minors could consent to abortion. The marriage effect appears to be largely explained by a reduction in marriages resulting from unplanned pregnancies; the estimated declines in so-called "shotgun" marriages are of similar magnitude as those in marriages overall.

Trends in sexual behavior by cohort of birth observed in Cycles 3-5 of the National Survey of Family Growth (NSFG) provide suggestive evidence that may help to explain the pill's lack of power in delaying marriage and motherhood. Cohorts whose members were increasingly able to consent to the pill as teenagers engaged in sexual intercourse and accessed family planning services at a younger age. The magnitudes of the changes suggest that there likely was a decrease in the probability of pregnancy conditional on having sex, but this effect was offset by the large increase in the number of teenagers who were sexually active. Overall, the evidence suggests that there was little change in the number of pregnancies. Access to legal abortion, however, permitted women to terminate more of those pregnancies, resulting in a reduction in births. 


\section{Trends in age at first marriage and birth}

Figure 1 describes the cumulative probabilities of marrying and giving birth for cohorts of women born between 1935 and 1960 observed in the 1979-1995 CPS June Fertility Supplements. ${ }^{1}$ Consistent with the view that dramatic changes took place in the lives of women coming of age in the sixties and seventies, there are large declines in the probabilities of marrying and giving birth at a young age. Between the 1940 and 1960 birth cohorts, the number of women in the sample who married before age 21 fell by 23 percentage points while the number who gave birth before age 22 declined by 19 percentage points.

The timing of these changes is coincident with the timing of the two major milestones in reproductive control: the introduction of the pill in 1960 and the national legalization of abortion in 1973. The reductions in the probabilities of marrying and giving birth before age 21 begin with the 1940 cohort of women who were 19 or 20 years old when the pill was introduced and continue for cohorts born over the next six years, coincident with increased access to the pill due to the repeal and invalidation of state Comstock laws. These trends then slow or arrest with the cohorts born in the late 1940s and early 1950s, and a second decline begins, roughly, with the 1955 cohort of women who were 18 years of age when abortion was legalized nationwide. The national legalization of abortion, however, occurred in the midst of a five year period in which there was a flurry of state-level legislation making it easier for minors to consent to the pill and to abortion, and so some of these latter reductions might also reflect the effects of these laws.

\footnotetext{
${ }^{1}$ I use the CPS June Fertility Supplement for every year between 1979 and 1995 in which it is available and contains information about both age at first marriage and birth. These years are 1979-1983, 1985-1988, 1990, 1992, and 1995. The sample used to create these summary statistics is limited to women aged 22 and older born from 1935 to 1960, yielding a total sample size of 308,481 .
} 


\section{Coding of legal changes}

Table 1 summarizes the years in which changes in the regulatory environment in each state first affirmed the rights of adult and minor women to consent to contraception and abortion. As summarized by the table, state-level variation in the timing of the removal of Comstock laws and the legalization of abortion combined with distinctions made in states' laws between young women's ability to consent to each resulted in variation across states and over time in access to reproductive control. In a given year between 1960 and 1976, a young woman might have been able to consent to neither contraception nor abortion, to both, or to one and not the other.

The policy environments governing access to reproductive control have been described by Goldin and Katz (2002), Bailey (2006), Guldi (2008), and Hock (2008). However, there is substantial variation across these sources in the coding of the years in which specific legal changes in each state granted young women confidential access to the pill. As mentioned in the introduction, the coding of the year in which unmarried teens could first consent to the pill differs between these studies for 35 states. Only Guldi (2008) and Hock (2008) address minors' ability to consent to abortion, and there are substantial differences between these two studies as well: the authors differ on the year in which unmarried women under age 18 gained confidential access to abortion for 19 states.

The coding presented in Table 1 is the result of a new, independent and extensive review of state policies based on sources that include annotated statutes, judicial rulings, attorney general opinions, advisory articles in state medical journals and law reviews, and newspaper accounts of legal changes, clinic openings, hospital policies, and enforcement actions. ${ }^{2}$ I describe the results of this new review in detail in Myers (2012), which includes an overview of reproduc-

\footnotetext{
${ }^{2}$ When possible, the information is checked against that in other reviews that cover contraception or abortion during some portion of this period. The most comprehensive of these are DHEW (1978), which provides profiles of state regulatory environments in the mid-seventies, and Merz et al. (1995), which provides a history of the enforcement of parental involvement laws for abortion through 1994.
} 
tive policy in the sixties and seventies, a state-by-state review of the relevant regulations, and a detailed explanation of the criteria used for the coding of dates presented in Table 1 in this paper.

Appendix A reproduces tables from Myers (2012) comparing and reconciling my suggested coding with that of Goldin and Katz (2002), Bailey (2006), Guldi (2008) and Hock (2008). In comparing the year in which teenagers are coded as first gaining confidential access the pill (Table A-1), the dates presented here prove similar to those reported by Hock (2008), whose coding differs from that in this paper for 8 out of 51 states. In contrast, my coding differs from that used in Guldi (2008) for 16 states, Bailey (2006) for 20 states and from Goldin and Katz (2002) for 27 states.

The majority of the discrepancies in the coding of access to the pill appear to reflect previous errors rather than different interpretations of an ambiguous legal environment. Bailey and Guldi have since released a working paper that revises the coding in their original papers (Bailey et al., 2011). Their revised coding of access to the pill corresponds more closely with my own independent coding, but still differs for 14 states. Of these remaining discrepancies, the most frequent explanation (occurring for 8 of the 14 cases) is that in states where the age of majority was once set at a lower level for women than for men, Bailey and Guldi assert that the age-of-majority threshold did not apply to the ability to consent to medical care. As discussed in greater detail in Myers (2012), I have not been able to find evidence that supports this assertion, whereas a review of the statutory language, citing judicial rulings, and secondary sources interpreting the laws indicate that they applied to a variety of rights, mostly likely including that to consent to medical care. While this disagreement in coding remains unresolved, the affected states tend to be small in population, and the results presented in this paper are similar to those obtained if I instead using Bailey and Guldi's (2011) revised coding of access to the pill. ${ }^{3}$

\footnotetext{
${ }^{3}$ Results using Bailey and Guldi's revised coding are available from the author upon request.
} 
Table A-2 of Appendix A compares the dates in which I have coded women under age eighteen gaining access to confidential legal abortion services with the coding in Guldi (2008) and Hock (2008). My coding differs from Guldi's for 14 states and from Hock's for 13 states, but there is very little overlap in these two sets. Where my coding differs from Guldi's, I consider only four states (Florida, Hawaii, New Jersey, and North Carolina) to reflect different interpretations of an ambiguous legal environment. The remaining ten states for which our coding differs appears to be the reflect errors in coding; for eight of these cases, my coding independently agrees with that of Hock. In contrast, where my coding differs from that of Hock, 12 of the 13 differences could be viewed as the result of differing interpretations of ambiguous legal environments. The most common difference in interpretation arises in the case of six states (Colorado, Florida, Indiana, Kentucky, Missouri, Nebraska) in which judicial rulings in 1974 and 1975 invalidated parental involvement laws. Whereas Guldi and I treat such rulings as granting de facto access for minors unless there was some other restrictive statute not addresses by the ruling, Hock requires explicit recognition of this right by the legislature. In Myers (2012) I note that the language of many of the court rulings striking down parental consent requirements strongly suggests that the ruling confirms the right of minors to consent. Paul et al. (1976) also treat the rulings as granting access in their review of the then current regulatory environment. It is difficult to judge, however, how willing providers may have been to supply confidential abortions to minors based on judicial rulings as opposed to legislative statutes. In the case of Florida, press accounts suggest that some hospitals responded to a 1975 ruling by beginning to provide abortions to minors without parental consent while others did not (Myers, 2012). This ambiguity in the ability of minors to legally consent to abortion affects a small number of states and years covered by the analysis, and the results described in subsequent sections are robust to using Hock's coding. ${ }^{4}$

\footnotetext{
${ }^{4}$ Results using Hock's (2008) coding for these six states are available upon request.
} 


\section{Empirical Strategy}

In this paper I adopt a quasi-experimental research design to estimate the effects of the introduction of the the pill, the legalization of abortion, and laws permitting young women to access each confidentially. The empirical model relies on a series of standard differences-in-differences specifications using linear probability models that include fixed effects for state of residence and year of birth as well as state linear time trends:

$$
\begin{aligned}
& I\left(\text { Age at first occurrence }_{\text {iys }}<k\right)=\beta_{0}+\text { pilllegal }_{y s k} \beta_{p l}+\text { consentpill }_{y s k} \beta_{p c}+ \\
& \text { abortlegal }_{y s k} \beta_{a l}+\text { consentabort }_{y s k} \beta_{a c}+R_{i} \boldsymbol{\beta}_{X}+v_{s}+v_{y}+v_{s x y}+\epsilon_{i y s k} .
\end{aligned}
$$

The dependent variable indicates that an event has taken place for woman $i$ born in year $y$ residing in state $s$ prior to the ages of $k=\{16,17, \ldots, 21\}$. Three outcomes are considered: first marriage, first birth, and a first marriage that is followed in less than 8 months by a first birth, which is termed a "shotgun marriage." Hence, in the case of marriage, for instance, a series of models are used to estimate the probabilities of having married prior to ages 16,17 , and so on. ${ }^{5}$

On the right-hand-side, $R_{i}$ is a vector of dummies for the race and ethnicity of woman $i, v_{s}$ represents individual state fixed effects to control for timeinvariant state characteristics, $v_{y}$ represents individual year-of-birth fixed effects to control for state-invariant temporal shocks, and $v_{s x y}$ is a set of state linear cohort trends that are included in some models to account for differences across states in fertility and marriage trends. The standard errors are corrected for

\footnotetext{
${ }^{5}$ This estimation strategy can be thought of as a survival analysis approach that does not adopt parametric assumptions regarding the hazard function. The linear probability approach used here is flexible regarding the hazard function, allows for time-varying covariates, provides easily-interpretable marginal effects, and can be directly compared to the results of previous researchers who have estimated similar models for a single age $k$. The survival function is not restricted to be non-decreasing, although the estimated functions do satisfy this requirement. The results are similar if this restriction is imposed by limiting successive samples to women for whom the event had not occurred in previous periods. The results are similar using probit models.
} 
correlation across individuals and over time in a given state by clustering at the state level as suggested by Bertrand et al. (2004). ${ }^{6}$

The variables of interest are pill legal, consent pill, abort legal, and consent abort. These measure the fraction of years between age 14 and age $k-1$ in which the legal environment permitted a woman born in state $s$ in year $y$ to access the pill, but only with parental consent (pill legal), to access the pill without parental consent (consent pill), to obtain an abortion only with parental consent (abort legal), and to consent to abortion (consent abort). Hence, the model estimates the effects of exposure to three mutually exclusive and collectively exhaustive legal environments governing access to each form of reproductive control at a given age: it is not legally available (the omitted category), it is legally available but minors cannot consent, and it is legally available and minors can consent. In models where the outcome is giving birth, the lag between conception and observation of the outcome is accounted for by lagging the policy variables by a year.

The sample is limited to cohorts of women born between 1935 and 1958 who are aged 22 and older at the time of observation. The oldest cohort was born in 1935 and was 25 years old when the pill was introduced and 38 when abortion was legalized nationwide. The youngest cohort was born in 1958 and was 2 years old when the pill was introduced and 15 when abortion was legalized nationwide. I choose to end with the 1958 cohort because this is the last cohort of women to reach majority before the 1976-1979 period during which the legal status of many state consent laws was unclear pending the resolutions of a series of U.S. Supreme Court cases beginning with Planned Parenthood v. Danforth. The restriction to women aged 22 and older ensures that the sample of women used for modeling outcomes prior to each age from 16 through 22 does not vary.

\footnotetext{
${ }^{6}$ Standard errors calculated with a block bootstrap approach are similar to those reported here.
} 


\section{Results}

Table 2 presents estimates of the effects of reproductive control on the probabilities of giving birth, marrying, or having a "shotgun marriage" prior to age 19. Model 1 includes only one measure of the reproductive policy environment: the proportion of previous years that an unmarried woman could legally consent to the pill in her state of residence. The estimated effects of confidential access to the pill are small and statistically insignificant for all three outcomes. Model 2 includes controls for whether the pill was legally available to adults, and Model 3 adds controls for access to abortion. There continues to be little evidence that access to the pill led to substantial delays in motherhood or marriage, but the results in Model 3 indicate that state policies granting access to abortion did have this effect. Adding state-cohort linear time trends in Model 4 increases the magnitude of the estimated effects of state abortion policy, which suggests the estimated effects in Model 3 should not be attributed to decreasing fertility trends in states granting greater access to abortion that would have occurred in the absence of these policies.

To illustrate the magnitude of the estimating effects, consider a woman who faced the same policy environment in all previous years of age from 14 through 17. Using the results from Model 4, a woman who lived in a state where abortion was legally available but where minors had not been granted confidential access (abortion legal $=1$ and consent abortion $=0$ ) is estimated to have been 2.8 percentage points less likely to give birth $(p<0.001)$ prior to age nineteen than if she lived in a state where abortion was not legally available at all. If state law granted minors confidential access to abortion (abortion legal $=0$ and consent abortion $=1$ ), the estimated effect increases to a 5.0 percentage point decrease in the probability of giving birth $(p<0.001)$, and the 2.2 percentage point difference between the effects of the two types of abortion policy is statistically significant $(p=0.003)$. 
Turning to the effects of reproductive control on the probability of marriage, the estimates again suggest that it is access to legal abortion and not to the pill that had large negative effects. Considering the estimated effects in Model 4 , women living in states where abortion was legal are predicted to have been 4.1 percentage points less likely to marry $(p=0.002)$ and 3.2 percentage points less likely to have a "shotgun marriage" $(p<0.001)$ prior to age 19. If minors had been granted confidential access, these effects increase to a 5.5 percentage point reduction in the probability of marriage $(p=0.001)$ and a 5.6 percentage point reduction in the probability of a "shotgun marriage" $(p<0.001)$. The amplifying effect of minors' legal ability to consent is statistically significant for "shotgun marriage" (difference $=-0.024, p=0.001$ ), but not for marriage (difference $=-0.014, p=0.450$ ).

Table 3 expands the results to report estimated coefficients from Model 4 over all ages from 16 through 21 for marriage and, to account for the lag between conception and birth, over ages 16 through 22 for birth. To provide a sense of the size of the estimated effects relative to the predicted probability of each outcome absent reproductive control, I also report average adjusted predicted cumulative probabilities assuming no in-state access to the pill or legal abortion. ${ }^{7}$ These probabilities are reported in the first row of each panel of Table 3. The 2.8 percentage point reduction in the probability of giving birth prior to age 19 due to the legalization of abortion, for instance, represents a 17 percent reduction relative to the adjusted predicted probability of 16.2 percent in an environment with no access. Similarly, the 5.0 percentage point reduction that is predicted if abortion is both legal and minors can consent represents a 31 percent reduction relative to an environment with no access.

The results of the full analysis reported in Table 3 can be more easily interpreted in Figures 2-4, which graph the predicted cumulative probabilities of

\footnotetext{
${ }^{7}$ Average adjusted predicted cumulative probabilities are calculated by using the estimated coefficients for each regression to predict the probability that the outcome equals one for each woman in the sample after setting the four measures of reproductive control equal to zero.
} 
each outcome for different reproductive policy environments. Figure 2, which presents the predicted cumulative probabilities of birth, shows that access to the pill is estimated to have had little effect on fertility for young women. The largest of the point estimates of the effect of the legal environment governing access to the pill corresponds to a 1.0 percentage point point decline in the probability of birth prior to age 20 for women who could consent to the pill, but the estimate is highly imprecise $(p=0.540)$. By age 20 the estimates indicate that the availability of the pill may even have led to a slight increase in births, though these estimates, like all of the coefficients for the pill in the models of fertility, are not statistically significant. In contrast to the evidence that the pill had little if any effect on the probabilities of giving birth prior to ages 16 through 22, the estimates indicate that the availability of legal abortion had large effects in delaying motherhood over all ages examined. Women living in states where abortion was legal were on average 4.5 percentage points less likely to give birth as teens $(p=0.001)$, for example, than women living in states where abortion was not legal. Moreover, the point estimates suggest that laws granting minors confidential access to abortion tend to amplify the effect of the legalization of abortion, and the differences in the point estimates are statistically significant at age 18 (difference $=-0.012, p=0.061$ ), age 19 (difference $=-0.022, p=0.003)$ and age $20($ difference $=-0.042, p=0.004)$.

Figure 3 summarizes the estimated effects of reproductive control on the cumulative probability of marriage. As with fertility, the estimates fail to provide evidence that the introduction of the pill lead to a reduction in the probability of marriage at a young age. The results suggest that the introduction of the pill may even have led to small increases rather than decreases in the probabilities of marriage before ages 17 through 20. The coefficient on pill legal indicates that women living in states where the pill was available but minors could not consent were 2.1 percentage points more likely to marry as teens $(p=0.043)$ than if the pill were not available at all. This is consistent with the suggestion 
in Edlund and Machado (2011) that legal environments in which the pill was only available to adults or married women may have encouraged young women to marry in order to obtain the pill. The coefficients on consent pill, though, also are sometimes positive, albeit statistically insignificant and smaller than the coefficients on pill legal. This cannot be explained by young women seeking to access the pill via marriage because these laws specifically permitted young women to consent to the pill if they were not married. The estimated positive effects of the pill on marriage therefore potentially present something of a puzzle.

In contrast to the evidence that the pill had little (and possibly positive) effects on the probability of marriage at a young age, access to abortion is estimated to have led to declines in the probability of marriage prior to all ages that are examined. As shown in Figure 3, the legalization of abortion is associated with delayed marriage, and the point estimates suggest an amplification effect of laws permitting young women to consent to abortion on the probabilities of marriage prior to ages 17 through 20 . The differences in the coefficients, however, are not statistically significant save for that at age $18(p=0.001)$.

The estimated reductions in the probability of marriage due to the legalization of and ability to consent to abortion reported in Table 3 for each age $k$ correspond to observably similar reductions in the probability of birth prior to age $k+1$, which suggests that increased access to abortion led to reductions in the probability of marriage at a young age primarily by allowing women who might once have married in response to an unplanned pregnancy to instead terminate that pregnancy. This conclusion is also supported by the results from the models of "shotgun marriage," which are presented in Table 3 and depicted graphically in Figure 4. Access to legal abortion in a woman's state of residence is associated with large drops in the probability of shotgun marriage across the ages examined, and the absolute magnitudes of the declines are similar to the magnitudes of the reduction in the probability of marriage by the same year of 
age and the probability of having given birth by the end of the following year. The probability of having had a "shotgun marriage" prior to age 19, for instance, is estimated to decline by 5.6 percentage points $(p<0.001)$ if abortion is legally available and minors can consent to it. The corresponding declines in the overall probabilities of marriage by age 19 and birth by age 20 are 5.5 percentage points and 8.7 percentage points, respectively.

\section{Alternative Sub-Samples of the Data}

As a whole, the evidence suggests that access to abortion led to large reductions in the fraction of young women entering marriage and motherhood, while access to the pill had little if any effect. Estimates of average effects for the population as a whole, though, could mask substantial variation across states and socioeconomic and demographic groups. Table 4 provides additional results from estimating the empirical specification in Equation 1 for various sub-samples of the data. Column 1 reproduces the corresponding estimates for the full sample from Table 2, Model 4.

\section{Estimates by race}

The separate estimates for (non-Hispanic) whites and blacks in Columns 2 and 3 of Table 4 suggest that the policy environment governing reproductive control had different effects for white and black women. Though neither is statistically significant, the point estimates suggest that the ability to consent to the pill may have led to a small decline in the probability of birth for white women and a larger increase in the probability of birth for black women. The estimated effects of the legalization of abortion are larger in magnitude, statistically significant, and negative for both whites and blacks, though they suggest that the fertility effects of access to abortion were much greater for blacks. White women who had access to abortion with parental consent are estimated to have been 1.6 percentage points less likely to give birth prior to age $19(p=0.044)$, while black 
women are estimated to have been 8.6 percentage points less likely to do so $(p=$ 0.016). If the legal environment permitted them to obtain an abortion without parental consent, the magnitudes of the reductions increase to 3.6 percentage points for whites $(p<0.001)$ and 14.4 percentage points for blacks $(p=0.002)$.

There are several possible explanations for the greater effect of the legalization of abortion for blacks. Prior to the legalization of abortion at least some physicians were willing to provide abortions to trusted patients or to refer them to another physician, either locally or abroad, who would provide the service (see, e.g. Joffe, 1995). Racial discrimination in the provision of medical care may have made it less likely that black women had a regular physician or could access other providers of illegal abortions. Moreover, to the extent that race was (and remains) strongly correlated with socioeconomic status at the time that these women came of age in the 1960s and 1970s, the differences in the effects of reproductive control by race may reflect the unobserved effects of socioeconomic status. Low-income women were presumably less likely to have a regular physician and less likely to be able to afford to travel internationally to obtain an abortion. ${ }^{8}$ Socioeconomic status also could explain the (statistically insignificant) positive effect of the pill on births for black women. Akerlof et al. (1996) suggested that the the pill may have created a "technology shock" effect in which its existence generated pressure to engage in sex regardless of whether the technology actually was adopted, leading to an increase in pregnancies among young unmarried women. This could have been particularly true for low-income teens who likely had more limited access to prescription contraception.

\section{Estimates omitting reform states}

The estimated effects of the legalization of abortion rely on six "repeal states" that legalized first-trimester abortions under most circumstances prior to the U.S. Supreme Court decision in Roe v. Wade that resulted in nationwide

\footnotetext{
${ }^{8}$ Common international destinations to obtain abortions were Mexico, England, Japan, and Sweden (Joffe, 1995).
} 
legalization in $1973 .{ }^{9}$ This approach groups the thirteen "reform states" that permitted abortion to preserve the physical or mental health of the mother together with the remaining non-reform states that prohibited abortion for any reason except to save the life of the mother. ${ }^{10}$

In fact, there was substantial variation the number of legal abortions performed in reform states, and in some the abortion ratio (abortions per 1,000 live births) rivalled or exceeded those in repeal states which had legalized abortion under most circumstances. In 1971 the reported legal abortion ratio for four reform states was 18.1 in Arkansas and 16.6 in Georgia, but 277.1 in Kansas and 144.8 in Maryland. For comparison, the abortion ratio in two repeal states was 212.2 in Washington state and 344.36 in California (Smith and Bourne, 1973). Anecdotal and empirical evidence suggests that the higher abortion ratios in some reform states may reflect a greater willingness or ability among providers to use the mental health standard. In Maryland, for example, mental health was the indication for 96 percent of legal abortions performed in the first six months of 1971 (Melton et al., 1972). ${ }^{11}$ If it is indeed the case that abortions were much more widely available in some reform states than in non-reform states,

\footnotetext{
${ }^{9}$ The repeal states were Alaska (1970), California (1969), D.C. (1971), Hawaii (1970), New York (1970), and Washington (1970). Repeal took place in four of the states, Alaska, Hawaii, New York, and Washington, by action of the state legislatures. California was both a reform and a repeal state; it had reformed its abortion laws in 1967, but a court ruling in late 1969 had the practical effect of legalizing abortion. Abortions became available at several clinics in D.C. following a 1971 court decision regarding the interpretation of the District's pre-existing mother's health standard for the provision of abortion. Court rulings in 1972 in New Jersey and Vermont also invalidated anti-abortion laws in those states. Garrow (1998) and Myers (2012) provide evidence that these rulings had little practical effect. The New Jersey Attorney General threatened to (and did) prosecute any physician performing an abortion, and Vermont hospitals did not immediately change their abortion policies. I, like Joyce et al. (2010), do not view these two states as repeal states.

${ }^{10}$ The reform states were Arkansas (1969), California (1967), Colorado (1967), Delaware (1969), Florida (1972), Georgia (1969), Kansas (1970), Maryland (1968), New Mexico (1969), North Carolina (1967), Oregon (1969), South Carolina (1970), and Virginia (1970). In addition, the District of Columbia had legalized abortion to preserve the life or health of the mother in 1901, and in 1944 the Massachusetts Supreme Court had interpreted that state's anti-abortion law to exempt abortions to preserve the woman's life or physical or mental health.

${ }^{11}$ See Myers (2012) for more evidence of substantial inter-state and inter-hospital variation in the provision of abortions under the mental health standard. Joffe (1995) also includes providers' first-hand accounts of variation in the application of mental health standards between hospitals and states.
} 
then omitting reform states from the sample of control states should increase the magnitude of the estimated effects of the legalization of abortion. Column 4 of Table 4 presents these results, which are consistent with this prediction for all of the examined outcomes. When reform states are omitted from the sample, the estimated effect of the legalization of abortion on the probability of giving birth prior to age 19 increases in magnitude from a 2.8 percentage point reduction $(p<0.001)$ to a 4.0 percentage point reduction $(p=0.001)$ if minors could not consent, and from a 5.0 percentage point reduction $(p<0.001)$ to a 6.5 percentage point reduction $(p<0.001)$ if minors could consent.

Exploring the possible role of interstate travel to access legal abortion Another reason to expect estimates of the effects of the legalization of abortion that rely on the repeal/non-repeal state dichotomy to be conservative is that they fail to account for interstate travel to obtain abortions in repeal states from 1970 to 1972. Joyce et al. (2010) compile evidence from CDC abortion surveillance to show that 42 percent of legal abortions performed in 1971 were provided to out-of-state residents, with most occurring in California, New York, and Washington D.C.. ${ }^{12}$ Because many women already were traveling to obtain abortions in these repeal states, the legalization of abortion in their home states likely had less effect. Joyce et al. (2010) argue that interstate travel to repeal states may also have confounded estimates of the effects of confidential access to the pill. States that granted early legal access to the pill in the 1970-1972 period tended to be close to New York, and so previous authors may have been picking up access to abortion in that state rather than the effect of increased access to the pill. Joyce et al. (2010) demonstrate that once they control for distance to a legal abortion provider, estimates of the average effect of confidential access to the pill on birth rates decline. It is possible, however, that this masks a larger effect of confidential access to the pill within the subset of states that

\footnotetext{
${ }^{12}$ Their geographic isolation made Alaska and Hawaii less attractive destinations, while Washington state included a residency requirement in its repeal law.
} 
were distant from legal abortion providers.

In the final column of Table 4, I restrict the sample to repeal states and states that are more than 500 miles from California, New York, and Washington D.C. as measured by the distance between the states' population centers (U.S. Census Bureau, 2010). The table refers to this group of states as "limited interstate travel states" because prior to the legalization of abortion, travel to another state to obtain a legal abortion was impossible (repeal states) or relatively costly (states that are distant from repeal states). ${ }^{13}$ The coefficient on the measures of legal access to abortion in all of the models increase in magnitude when one restricts the sample in this way. Interestingly, the estimated effect of confidential access to the pill in reducing the probability of birth is now larger in magnitude and statistically significant, albeit one-third the size of the estimated effect of confidential access to abortion. Confidential access to the pill is associated with a 2.4 percentage point reduction in the probability of giving birth before age $19(p=0.043)$ while confidential access to abortion is associated with a 6.4 percentage point reduction $(p<0.001)$. Taken together, these results suggest that travel to nearby states to access abortion tended to reduce the salience of own-state policies related to access to both the pill and abortion. The diffusion of greater access to the pill and abortion to young women in the early 1970s may have had much greater effects on fertility and marriage if women had not already been traveling across state lines to access abortion.

\section{Comparison to previous findings}

The "power of the pill literature" is primarily based on two seminal papers, Goldin and Katz (2002) arguing the diffusion of the pill to young unmarried

\footnotetext{
${ }^{13}$ The states in this sample are Alabama, Alaska, Arkansas, California, Colorado, the District of Columbia, Florida, Georgia, Hawaii, Idaho, Illinois, Indiana, Iowa, Kansas, Louisiana, Minnesota, Mississippi, Missouri, Montana, Nebraska, New Mexico, New York, North Dakota, Oklahoma, Oregon, South Dakota, Tennessee, Texas, Utah, Washington, Wisconsin, and Wyoming. The 500 mile cutoff is admittedly arbitrary, but the findings are substantially the same using a 750 or 1,000 mile cut-off.
} 
women led college-educated women to delay marriage and pursue advanced degrees, and Bailey (2006) arguing that the pill led to delayed fertility and increased labor supply among young women. These papers have been widely cited in the literature. Google Scholar reports citation counts of 406 for Goldin and Katz (2002) and 111 for Bailey (2006), and REPEC ranks Goldin and Katz (2002) in the top 1 percent of papers by citations. ${ }^{14}$ The coding of legal access to the pill presented in these papers also has been used by subsequent researchers including Zuppann (2012) using Goldin and Katz's coding and Steingrimsdottir (2010) and Edlund and Machado (2011) using Bailey's coding. I have examined similar outcomes as Goldin and Katz (2002) and Bailey (2006) - the probabilities of marrying and giving birth prior to selected years of age- and now attempt to reconcile the differences in our findings. ${ }^{15}$

When estimating the power of the pill in reducing the probability of marriage, Goldin and Katz (2002) focus on college-educated women while I have examined the effect for the population of women as a whole. In Table 5 I present the results of models for the same outcome as that in Goldin and Katz: the probability of marriage prior to age 23 for women who are aged 22 and older and have completed college at the time of observation. In the first panel I use Goldin and Katz's data and sample. ${ }^{16}$ In Column 1 of Panel 1, I use their

\footnotetext{
${ }^{14}$ The Google Scholar search was performed on June 28, 2011. The REPEC ranking was observed on the same date and was valid both for ranking by number of citations weighted by recursive impact factors and for number of citations weighted by recursive impact factors and discounted by age.

${ }^{15}$ Guldi (2008) and Ananat and Hungerman (2008) also examine fertility effects, but do so using birth rates instead of the cumulative probability of having become a mother, so the results are not directly comparable to mine. Ananat and Hungerman (2008) do not control for confidential access to abortion, and estimate that births to women aged 14 to 20 declined by 21 percent in states where minors could consent to the pill. This is a very large effect that is nearly twice as large as the estimated effect of the legalization of abortion on teen birth rates in Levine (2003). Unlike Ananat et al., Guldi (2008) controls for confidential access to abortion as well as to the pill. Her findings indicate that confidential access to the pill led to an 8 percent decline in fertility for white women aged 15 to 21 , though the effect disappears if she uses monthly instead of annual natality data. Joyce et al. (2010) demonstrate that when they stratify Guldi's sample into young (15-18) and older (19-21) age groups, so that identification is achieved by comparing the effects of access for more similarly-aged women, the estimated effects of confidential access to the pill also disappear.

${ }^{16}$ I thank Lawrence Katz and Claudia Goldin for graciously supplying me with their data and program files.
} 
coding and specification of the dates of legal changes to replicate the result from Column 1 of Table 4 in their paper showing that college-educated women were 2.0 percentage points less likely to be married before age $23(p=0.078)$ if they were born in a state that, by the time they were 18 years old, had granted minors under age 18 capacity to consent to the pill. In the second column, I re-estimate the model using my revised legal coding, and the estimated effect of the pill disappears, becoming small $(-0.0001)$ and statistically insignificant ( $p=0.994)$. When I add the detailed legal controls used in my models, the results, presented in the third column of the first panel, again indicate a very large effect of access to abortion but little effect of the pill.

In the second panel of the table, I estimate the same three models presented in the first panel using the CPS Fertility Supplement data used elsewhere in this paper instead of the 1980 Census IPUMs data. Interestingly, even using Goldin and Katz's coding of the dates of legal changes, the estimated effect of access to the pill is much smaller and statistically insignificant when I use the 1979-1995 CPS Fertility Supplements instead of the 1980 Census IPUMs data. This may be explained by the ability to observe women in the younger cohorts at later years of age using the CPS Fertility Supplement data. Goldin and Katz (2002) observe women born between 1935 and 1957 in the year 1980 only, when the older cohorts have had much more time to complete college than have the younger ones. The younger sample therefore is made up of women born in later years who not only completed college, but who did so by their early twenties, whereas the older cohorts may have completed college later in life. Though we cannot observe in either data set the age at which a college graduated completed college, it may be that Goldin and Katz (2002) are picking up some effect of the pill in delaying marriage for women who not only completed college, but who did so "on time." The effect of reproductive control may have been relatively greater for this group. ${ }^{17}$ In the final two columns of Table 5, I use my legal

\footnotetext{
${ }^{17}$ In unreported models in which I restrict the CPS sample to 1980 only, I obtain a similar
} 
coding and specification and again fail to find evidence that access to the pill delayed marriage for college graduates, while the estimated effects of access to abortion are large and statistically significant.

Appendix B expands on this exercise by first replicating the remainder of Goldin and Katz's models (nine in total) estimating the probability of marriage prior to age 23, and then exploring the sensitivity of the results in each of model to using CPS Fertility Supplement data and/or my revised legal coding. The results are generally consistent with those presented Table 5 and described above. The estimated effect of confidential access to the pill in delaying marriage for college graduates are not statistically significant and tend to be much smaller in magnitude when I estimate them using the CPS Fertility Supplement data, and once the legal coding is corrected, there is no evidence that access to the pill led to delayed marriage for college graduates. ${ }^{18}$

Turning to estimates of the effect of the pill on the probability of giving birth at a young age, Bailey (2006) estimates that women who could consent to the pill before age 21 were 7 percentage points less likely to give birth before age 22 . Bailey, however, has since released an addendum to this paper acknowledging errors in formatting the data and revising estimates of the effect of the pill on the probability of giving birth at a young age downward to at most a one to two percentage point decline (Bailey, 2009). I have presented point estimates that indicate that confidential access to the pill had no effect on the probability of giving birth. In either case- no decline or a 1 percentage point decline- the estimated effects are not large either in absolute magnitude or relative to the new estimates of the effects of the legalization of abortion and laws permitting minors to consent to it that have been presented in this paper.

Nevertheless, I also will attempt to reconcile the (small) differences in my findings and those of Bailey (2009). We both use data from the 1979-1995 CPS

point estimate as those of Goldin and Katz (2002) that are replicated in Column 1 of Panel A, though the sample size is small and the estimate is imprecise.

${ }^{18}$ Hock (2008) remarks in a footnote that he also does not find evidence of delayed marriage for college graduates using the 1968-1979 CPS Fertility Supplements. 
June Fertility Supplements and select similar year-of-birth cohorts, ${ }^{19}$ so the differences in the findings are most likely due to differences in sample selection criteria, the coding of state laws, or inclusion of additional controls for young women's access to abortion. With regards to sample selection, I restrict my sample to women aged 22 and older at the time of observation whereas Bailey restricts her sample to women aged 36 and older who had ever married and ever given birth and do not have allocated values on age at first birth. Bailey imposes the age restriction because she estimates effects on the probability of first birth through age 36 , but this has the practical effect of severely reducing the number of observations of women born in the latter birth cohorts who were more likely to be subject to liberalized abortion access but who didn't reach age 36 until the mid-nineties. In Bailey's sample, she observes the 1955-1958 cohorts in the 1992 and 1995 supplements only, obtaining a sample size of 5,105 women, whereas I observe members of these cohorts beginning with the 1979 supplement and obtain a sample of 61,603 women. Turning to the other restrictions, Bailey indicates that she restricts the sample to women who have ever given birth because they have information on age at first birth and to women who have ever married because the CPS only sampled ever-married women in 1986, 1987, and 1988. Neither restriction seems necessary. First, if a woman has not given birth, then one can readily infer that she had not given birth prior to each previous year of age and keep her in the sample. Second, the 1986-1988 CPS Fertility Supplements do, in fact, ask never-married women about age at first birth. ${ }^{20}$ Finally, I choose not to restrict the sample to non-allocated values of age

\footnotetext{
${ }^{19}$ Bailey's main specifications use 1935-1959 year of birth cohorts, while mine use 1935-1958 because the 1959 cohort was 17 in 1976 when the U.S. Supreme Court decision in Danforth created confusion about the validity of some state parental involvement laws.

${ }^{20}$ The 1987 and 1988 documentation indicates that "questions determining the...date of birth of youngest and oldest children were asked of women aged 18-44 years old" (United States Census Bureau, 1988, 1989). This also is supported by the questionnaires and data for 1987 and 1988. The 1986 documentation does state in the introduction that questions on fertility were asked only of ever-married women, but this appears to be an error in the codebook. The questionnaire directs the interviewer to ask all women aged 18-44 about the date of first birth regardless of their marital status, and the information is contained in the data for all women in the sampled age range regardless of marital history (United States Census
} 
at first birth out of concern that allocation is itself non-random. Approximately 10 percent of values on age at first birth are allocated, and the results are not sensitive to whether or not they are excluded.

In the first panel of Table 6 I use Bailey's (2009) sample to estimate the probability of having given birth prior to age $19 .^{21}$ In the first column, I report a similar estimate of the effect of confidential access to the pill: a 1.4 percentage point decline in the probability of birth $(p=0.029)$ as compared to Bailey's report of a 1.1 percentage point decline. ${ }^{22}$ In the second Column, in which I use my legal coding and Bailey's sample and specification, the point estimate is reduced by more than half and is not statistically significant. In the final column, in which I use Bailey's sample and my legal coding and specification, the estimates continue to indicate no effect of the pill and a large negative effect of the legalization of abortion if minors could not consent. The estimated effect of confidential access to abortion is small and statistically insignificant, but imprecisely estimated, likely due to the very small number women born in the late fifties who are aged $36+$ and hence appear in the sample. In the second panel of Table 6, I compare the results of different coding using the more expansive sampling criteria. In the first column I show that estimates based on Bailey's legal coding and specification but a broader sample, the estimated effect becomes much smaller and statistically insignificant. ${ }^{23}$ In the second column when I use my legal coding and Bailey's specification, this estimated effect increases slightly in magnitude and attains statistical significance, but in the third column when I add additional controls for access to abortion, the estimated effect of the pill

Bureau, 1987). I obtain similar results if I drop women appearing in the 1986 supplement from the data.

${ }^{21}$ Though I use the same restrictions reported by Bailey, our sample sizes are slightly different; she reports 112, 903 observations in the final sample while I have 104, 053 .

${ }^{22}$ This result corresponds to the estimates in Model 1 of Table IV in Bailey (2009). I reach similar conclusions using different ages and specifications from Bailey's addendum.

${ }^{23}$ If I relax each of Bailey's exclusion criteria in turn, the coefficient of interest becomes smaller, suggesting that all of the restrictions contributed to the larger magnitude of the point estimate in the restricted sample. The largest change in magnitude occurs when I relax the age exclusion criteria so that women aged 23 to 35 are no longer excluded from the analysis. 
again is small and statistically insignificant while the estimated effects of access to abortion are larger and statistically significant. ${ }^{24}$

Taken together, these comparisons of results suggest that the evidence that confidential access to the pill led to delayed marriage for college graduates (Goldin and Katz, 2002) and delayed fertility for a broader swath of women (Bailey, 2006, 2009) is at best substantially weakened when using corrected coding, alternative data sets and/or samples, and additional controls for access to abortion. Moreover, even the original estimates from the earlier literature are much smaller in magnitude than the new estimates of the effects of access to abortion presented here.

\section{Plausibility}

The results in this paper indicate that the pill was not particularly powerful in reducing the probability that a young woman entered into motherhood in the 1960s and 1970s, but that abortion was. Is this plausible?

The fertility effects of increased reproductive control are determined by behavior along a "fertility decision tree" (Levine, 2003) in which a woman chooses whether and when to engage in sexual intercourse, whether and what form of contraception to use, and, if pregnancy results, whether to terminate the pregnancy. It would be informative to be able to describe trends in sexual behavior for young unmarried women in the 1960s and 1970s, but, unfortunately, only two historical surveys prior to 1980 contain information on the sexual behavior and contraception use of young unmarried women prior to 1980, and both are small cross sections. ${ }^{25}$ To expand beyond the snapshots of sexual activity afforded by these studies, I summarize information by cohort of birth in Cycles

\footnotetext{
${ }^{24}$ The estimates in the last column of Table 6 do not correspond to those in Model 3 of Table 2 because I have followed Bailey in not including controls for race.

${ }^{25}$ The surveys are the National Survey of Young Women (1971) and The National Survey of Adolescent Female Sexual Behavior (1976). The National Fertility Survey, conducted in 1965, 1970, and 1975, asked some retrospective questions about the use of contraception, but the samples are limited to married or ever-married women. See Goldin and Katz (2002) for more information.
} 
3-5 (1982, 1985, and 1995) of the National Survey of Family Growth (NSFG), a nationally representative survey of women aged 15-44 that contains retrospective information about the age at and characteristics of first sexual intercourse for 14, 943 women born between 1939 and $1961 .^{26}$

Figure 5 summarizes age at first voluntary sexual intercourse following menarche reported by women the NSFG. Age at first sexual intercourse changes little for women born in the early to mid forties, cohorts that generally could not consent to the pill until after marriage or the age twenty-one, by which times the majority of them had already had sex. The probability of having had sex as a teen begins to increase with cohorts born in the late forties, and rises dramatically in the short span between the 1950 and 1955 cohorts who came of age at the time of increasingly liberalized access to the pill. Though I cannot observe whether the cohorts that had sex at increasingly young ages also were increasingly likely to use the pill, Figure 6 describes trends across birth cohorts in the cumulative probability of having received family planning services, which encompass obtaining the pill. ${ }^{27}$ Indeed, as with age at first sex, the most dramatic changes are observed for women born in the early fifties. Comparing the two figures, between the 1950 and 1955 cohorts, the fraction of women who had had sex before age 18 increased by 12 percentage points (from 0.35 to 0.47 ) and the fraction that had received family planning services before the age of 18 increased by the same amount (from 0.12 to 0.24 ).

While increased use of family planning services is consistent with the assertion that affirmative legal changes were salient to young women who wanted to access reproductive control, this need not have led to changes in fertility. If women were substituting pill-protected sex for condoms or abstinence, then there may have been little change in pregnancy rates. Consistent with this

\footnotetext{
${ }^{26}$ The lack of state identifiers in the public-use NSFG data precludes use of a difference-indifference estimation framework. Even with this information, the sample size is much smaller than in the CPS, and estimates likely would be imprecise.

${ }^{27}$ Age at first family planning visit is not available in Cycle 5. A related question was asked about date of first receipt of contraceptive services, but because the questions are not directly comparable, I do not use the Cycle 5 data.
} 
observation, the same cohorts born in the early to mid fifties that exhibit the largest decreases in age at first sex and increase in family planning visits in Figures 5 and 6 also are those that exhibit little change in the probability of giving birth in Figure 1.

A final piece of suggestive evidence on the use of contraception comes from Figure 7, which graphs the type of birth control used at first sexual intercourse by year-of-birth cohort. The sample is divided into two groups: women whose first sexual intercourse occurred after marriage and/or age twenty-one (29 percent of the sample) and women whose first sexual intercourse occurred before marriage and the age of twenty-one (71 percent of the sample). The first group was more likely to be able to legally consent to the pill at the time of intercourse and also to be better able to predict when sexual intercourse would occur for the first time. Not surprisingly, in comparing the two panels of Figure 7, it is evident that birth control use was much higher across all cohorts for the first group of women than the second. The relevant information in Figure 7, though, comes not from comparing levels of use, but from examining differences in trends across cohorts for the two groups. Looking at women who first had sex after marriage and/or age twenty-one, pill use increases dramatically for the cohorts born in the early forties, from 5.1 percent for women born in 1940 to 23.5 percent for women born just five years later. There is not much corresponding change in other forms of birth control, so the result is that women who had sex after marriage or age twenty-one became much more likely to use birth control at first intercourse, consistent with access to the pill leading to a large decrease in marital fertility as found by Bailey (2010). In contrast, there is little change in birth control use at first sex for young unmarried women. The diffusion of the pill for this group occurred most rapidly for cohorts born in the early fifties. Correspondingly, pill use at first intercourse remains low for cohorts born in the early forties- only 4 percent for the 1945 cohort- then begins to climb, reaching 14 percent by 1955 . As use of the pill increases, however, there is a partially 
offsetting drop in use of condoms, from 25 percent for the 1945 cohort to 19 percent for the 1955 cohort. This suggests that while pill usage was increasing, unmarried women were partly substituting from condoms. Overall, total birth control use at first intercourse conditional on engaging in sex increases relatively little, from 31 percent for the 1945 cohort to 34 percent for the 1955 cohort.

Although the increase in birth control use is less dramatic for young unmarried women, it still might result in an observable drop in the probability of pregnancy conditional on being sexually active because the pill is more effective than the condom. In the first year of typical use, 8 percent of women on the pill will become pregnant versus 15 percent using condoms and 85 percent using no method (Trussell, 2004). As a simple back-of-the-envelope calculation, assume that the failure rates for all other forms of birth control (which fewer than 3 percent of women in the sample used at first sex) were identical to the condom. Then, using the rates of contraception use depicted in Figure 7 for women who had sex before marriage and age 21, the probability of pregnancy in the first year of sexual activity was 63 percent for the 1945 cohort. ${ }^{28}$ Now consider the 1955 cohort. Their reported used of birth control is 3 percentage points higher than the 1945 cohort due to increased use of the pill, but this likely understates the true effect of the pill given that many women would have begun contracepting with the pill after they first had sex. Assume that the actual increase in the use of the pill was twice as high than reported at first sex- rather than 14 it was 28 percent, which is similar to the fraction that received family planning services by this age- and that all of this assumed increase is matched by an equal decrease in the percentage of women using no contraception at all. Then the probability of pregnancy in the first year for sexually active women in this cohort would be 49 percent. ${ }^{29}$ This rough back-of-the-envelope calculation predicts that sexually active teens could have experienced a 14 percentage point drop in the probability of pregnancy. Though this is a large decrease, it is important to note that

${ }^{28}$ This is calculated as follows: $0.85 * .69+0.15 *(0.25+.02)+.08 * 0.04$.

${ }^{29}$ This is calculated as follows: $0.85 * .52+0.15 *(0.19+.01)+.08 * 0.28$. 
it is in the probability of pregnancy conditional on having sex, which women in the 1955 cohort were much more likely to do. The predicted probabilities of pregnancy for all women in these cohorts using the fraction of women who had had sex by age 18 in Figure 5 are 20 percent for the 1945 cohort and 23 percent for the 1955 cohort. $^{30}$ Hence, this calculation suggests that pregnancy rates would increase by 3 percentage points between these cohorts. Though these are admittedly very rough approximations, they demonstrate that it is not implausible to estimate that the pill had small, possibly even positive, effects on fertility even if it decreased the probability of pregnancy among sexually active women.

Turning to the plausibility of the large effect of access to abortion in reducing fertility, I present some evidence on trends in use of abortion services. As with use of contraception, utilization of abortion services among young women is quite difficult to measure during this period, but also even in more recent years (see Dennis et al., 2009; Joyce et al., 2010). ${ }^{31}$ Cycle 4 of the NSFG includes imputed variables that can be used to measure trends in the probability of having an abortion at a young age, but respondents are known to substantially underreport abortions (NSFG, 1988). Another problem with observing trends over the cohorts of women is that those who could only access abortion illegally may be relatively less likely to report the abortion.

Figure 8 describes the proportion of women in Cycle 4 of the NSFG who report having had an abortion prior to ages 18 and 21. The proportion of young women reporting that they had abortions increases markedly for women

\footnotetext{
${ }^{30} 0.69 * 0+0.31 * 0.63=0.20$ for the 1945 cohort and $0.53 * 0+0.47 * 0.49=0.23$ for the 1955 cohort.

${ }^{31}$ The CDC began collecting information on the incidence of legal abortion by state of occurrence in 1969, but the data are incomplete because of differences in state reporting requirements. The Guttmacher Institute began gathering more detailed and complete information in 1974 based on survey of abortion providers that is the most widely-accepted estimate of the incidence of abortions in the United States. However, Guttmacher analysts caution against using their data to examine the effect of laws affecting young women because estimates by state of occurrence fail to account for interstate travel in response to legal changes, and estimates by state-of-residence still cannot accurately account for out-of-state travel because imputations are made based on age shares of abortion rates by state of occurrence (Dennis et al., 2009).
} 
born in the early fifties, coinciding with the repeal of abortion laws in five states in 1970 and the District of Columbia in 1971. Less than 1 percent of the cohort of women born in 1950 report having had an abortion before the age of eighteen while 5 percent of the cohort born in 1960 does so. If there was little corresponding change in the number of pregnancies- and the evidence on sexual activity and use of birth control in previous figures suggests that that is a reasonable assumption- the rise in the incidence of reported abortions would correspond to a predicted 5 percentage point decrease in births before age 19 . This is similar to the estimated declines in the probability of giving birth before age 19 presented in Table 2 .

The estimates also indicate that laws permitting minors to consent to abortion had an additional impact beyond the legalization of abortion. Is this plausible? Guldi (2008) also finds that minors' ability to consent to abortion led to a reduction in birth rates, though she estimates that the effect is larger for whites than blacks, while I find the opposite. When estimating the effect of parental involvement laws enacted between 1985 and 1996, however, Levine (2003) finds a statistically insignificant 3 percent increase in the teen birth rate and concludes that parental consent requirements did not have a large effect on teen births. The laws in this later period may have been less binding than the legal environment in the seventies, however, because judicial bypass was not available in any state in the early seventies while it was an option in all states enforcing parental involvement laws in the eighties and nineties. Teens also may have been less willing to involve a parent in the seventies. A 1991 survey of teens seeking abortions in states without parental involvement laws found that 61 percent had told a parent about the abortion (Henshaw and Kost, 1992), whereas in a similar survey from 1979-1980, 55 percent had done so (Torres et al., 1980). In the 1979-1980 survey, respondents were also asked what they would have done if parental notification had been required by the clinic. Twenty-three percent reported that they would not have come to the clinic and, of these, 40 percent said 
that they would have had the baby (Torres et al., 1980). Though it is difficult to judge how well this self-report of hypothetical behavior might correspond to the actual response to parental consent requirements, or what the cumulative effect of parental involvement might be by the age of 19, it does suggest that it is plausible that confidentiality mattered to minors seeking abortion services in the seventies.

\section{Conclusion}

The pill has been credited with sparking a sexual revolution, and allowing women to delay marriage and motherhood and to more reliably plan for careers requiring higher levels of education and greater labor force attachment. The evidence presented here indicates that in fact the diffusion of the pill to young unmarried women had little effect on age at first birth or marriage. It still is possible, however, that the pill was powerful in other ways. The diffusion of the pill is coincident with decreases in age at first sex, and it may have played some causal role in the sexual revolution even if this did not lead to delayed fertility or marriage. Moreover, the results presented here regarding the probability of giving birth before age 22 do not contradict the findings in Bailey (2010) that the introduction of the pill was associated with large changes in fertility for married adult women.

Unlike the pill, abortion was not a wholly new technology, but it was one that was once difficult to access. A woman living in a state where abortion was illegal and who wished to terminate an unwanted pregnancy had to risk a self-induced abortion, search locally for a provider who was willing to perform an illegal surgery, or locate and travel to a physician provider in another state or country where abortion was legal. The evidence presented here suggest that the associated risks and costs were prohibitive for many young women so that the legalization of abortion had a large effect on fertility and marriage for young women. Moreover, laws permitting unmarried women under age 21 to confiden- 
tially access legal abortion services had an additional impact, suggesting that the cost of obtaining parental permission also prevented some young women from obtaining an abortion during this period. In terms of delaying marriage and motherhood, confidential access to abortion rather than to the pill therefore appears to be the more salient form of increased reproductive control for young unmarried women in the 1960s and 1970s. If it is via these two mechanisms-age at first marriage and birth- that young women's reproductive control in turn influences other economic outcomes, then social scientists may wish to devote greater attention to the potential "powers" of abortion than of the pill. 


\section{References}

George Akerlof, Janet Yellen, and Lawrence Katz. An analysis of out-of-wedlock childbearing in the United States. The Quarterly Journal of Economics, 111 (2):277-317, 1996 .

Elizabeth Oltmans Ananat and Daniel Hungerman. The power of the pill for the marginal child: Oral contraception's effects on fertility, abortion, and maternal and child characteristics, 2008. Working Paper.

Bernard Asbell. The Pill: A biography of the drug that changed the world. Random House, 1995.

Martha Bailey. More power to the pill. The Quarterly Journal of Economics, 121(1):289-320, 2006.

Martha Bailey. More power to the pill: Errata and addendum. The Quarterly Journal of Economics, (Published online February 17, 2010), 2009.

Martha Bailey. "Momma's Got the Pill": How Anthony Comstock and Griswold v. Connecticut shaped U.S. childbearing. American Economic Review, 100 (1):98-129, 2010.

Martha Bailey, Melanie Guldi, Allison Davido, , and Erin Buzuvis. Early legal access: Law and policy governing contraceptive access, 1960-1980, 2011. Working paper.

Gary Becker. A Treatise on the Family. Harvard University Press, 1981.

Marianne Bertrand, Esther Duflo, and Sendhil Mullainathan. How much should we trust differences-in-differences estimates. The Quarterly Journal of Economics, 119(1):249-275, 2004.

Amanda Dennis, Stanley Henshaw, Theodore Joyce, Lawrence Finer, and Kelly Blanchard. The Impact of Laws Requiring Parental Involvement for Abortion: A literature review. Technical report, Guttmacher Institute, New York, 2009.

Lena Edlund and Cecilia Machado. Pill power: The prequel, 2011. IZA Working Paper No. 5468.

David Garrow. Liberty and Sexuality: The right to privacy and the making of Roe v. Wade. California University Press, 1998.

Nancy Gibbs. The Pill at 50: Sex, freedom, and paradox. Time Magazine, 175 (17), April 22, 2010.

Claudia Goldin and Lawrence Katz. The power of the pill: Oral contraceptives and women's career and marriage decisions. Journal of Political Economy, 110(4):730-770, 2002.

Melanie Guldi. Fertility effects of abortion and birth control pill access for minors. Demography, 45(4):817-827, 2008. 
Stanley Henshaw and Kathryn Kost. Parental involvement in minors' abortion decisions. Family Planning Perspectives, 24(5):196-207, 1992.

Heinrich Hock. The pill and the college attainment of American women and men, 2008. Working paper.

Carole Joffe. Doctors of Conscience: The struggle to provide abortion before and after Roe. Wade. Random House, 1995.

Ted Joyce, Ruoding Tan, and Yuxiu Zhang. Changes in teen fertility following access to the pill and abortion in the early 1970s, 2010. Working paper.

Phillip Levine. Parental involvement laws and fertility behavior. Journal of Health Economics, 22(5):861-878, 2003.

Robert Melton, King Seegar, and John Pitts. Therapeutic abortion in maryland, 1968-1970. Obstetrics and Gynecology, 39(6):923-929, 1972.

Caitlin Knowles Myers. Young women's access to abortion and contraception, 1960-present, 2012. Working paper.

"Oral contraceptives: The liberator". The Economist, 353(8151):102, December $25,1999$.

Eve Paul, Harriet Pilpel, and Nancy Wechsler. Pregnancy, teenagers, and the law, 1976. Family Planning Perspectives, 8(1):16-21, 1976.

Jack Smith and Judith Bourne. Abortion surveillance program of the center for disease control. Health Services Reports, 88(3):255-259, 1973.

Herdis Steingrimsdottir. Access to the birth control pill and young people's career plans, 2010. Working paper.

Aida Torres, Jacqueline Darroch Forrest, and Susan Eisman. Clinic policies and adolescents' use of family planning and abortion services. Family Planning Perspectives, 12(6):284-292, 1980.

James Trussell. Contraceptive failure in the United States. Contraception, 70 (2):89-96, 2004.

United States Census Bureau. Population and population centers by state, 2000.

United States Census Bureau. June 1986 CPS: Fertility, birth expectations, and immigration supplements technical documentation, 1987.

United States Census Bureau. June 1986 CPS: Fertility, birth expectations, and immigration supplements technical documentation, 1988.

United States Census Bureau. June 1986 CPS: Fertility, birth expectations, and immigration supplements technical documentation, 1989.

Andrew Zuppann. The pill and marital stability, February 17, 2012. Working Paper. 
Figure 1: Fraction of women who had married and given birth prior to ages 15-22, by year of birth
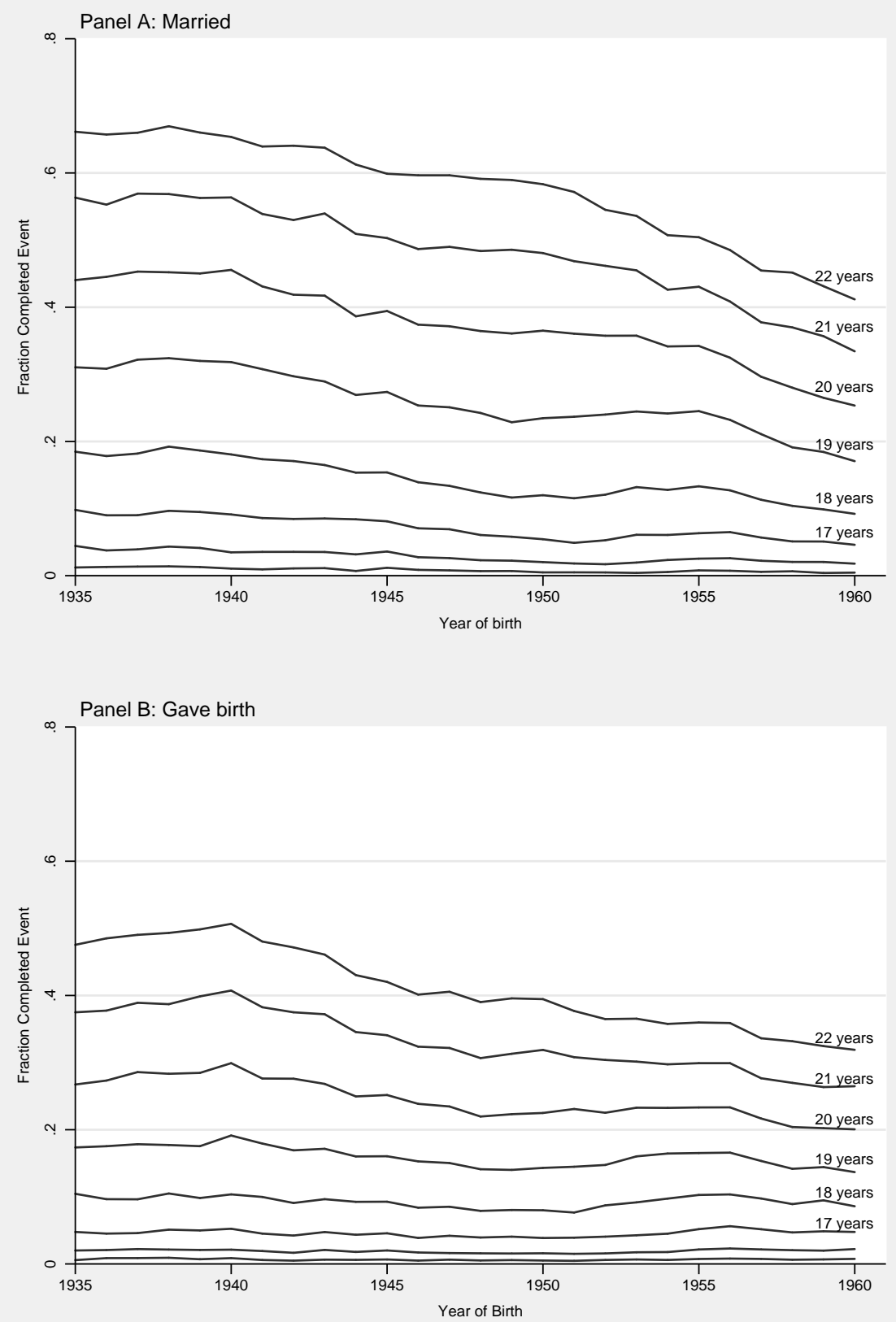

Source: Author's calculations using 1979-1995 CPS Fertility Supplements with information on age at both events. Sample: Women born between 1935 and 1960, who were aged 22+ at the time of observation $(n=308,481)$. Sampling weights are applied. 
Figure 2: Estimated effects of reproductive control on the cumulative probability of birth

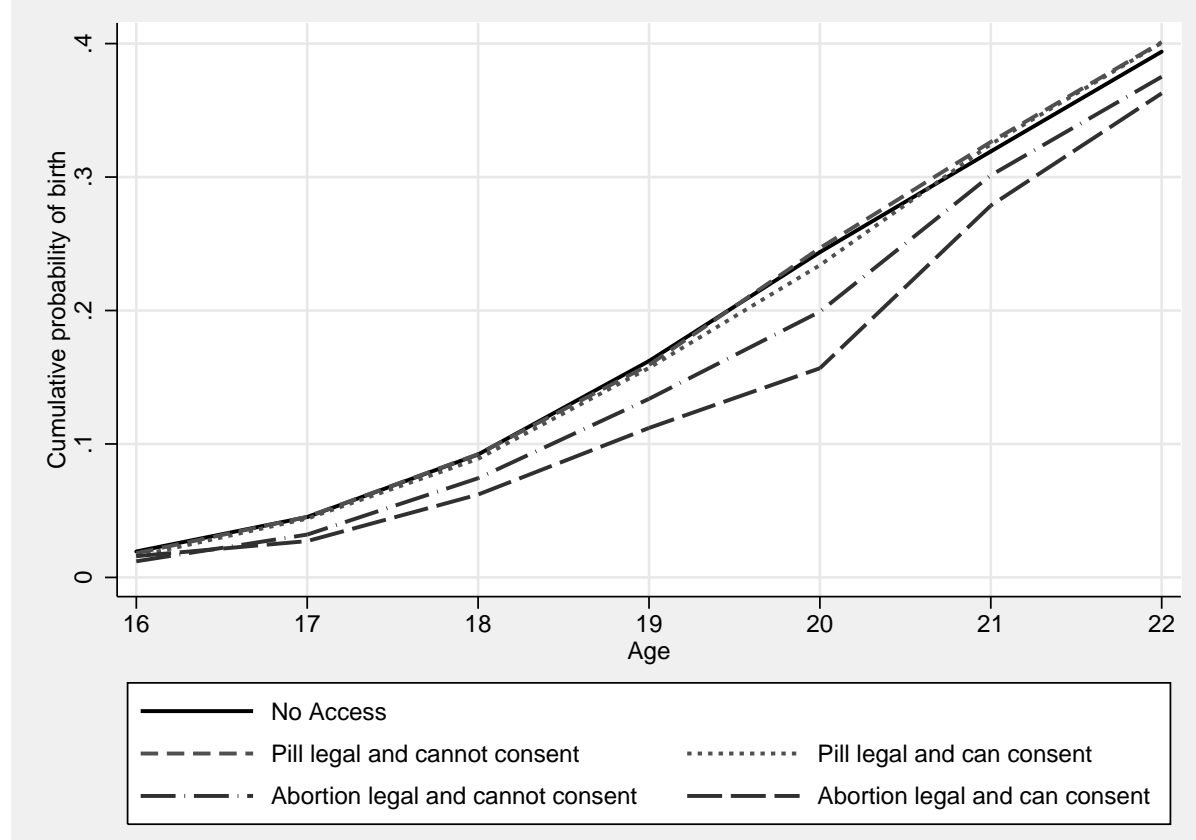

Average adjusted predicted cumulative probabilities of having given birth. Estimates are based on separate linear probability models of having given birth prior to each year of age from 16 through 21. Control variables include race and ethnicity, state fixed effects, year of birth cohort fixed effects, and state*cohort linear time trends. Data: CPS Fertility Supplements, 1979-1995. Sample: Women born between 1935 and 1958 who were aged 22+ at the time of observation $(\mathrm{n}=266,054)$. Sampling weights are applied. 
Figure 3: Estimated effects of reproductive control on the cumulative probability of marriage

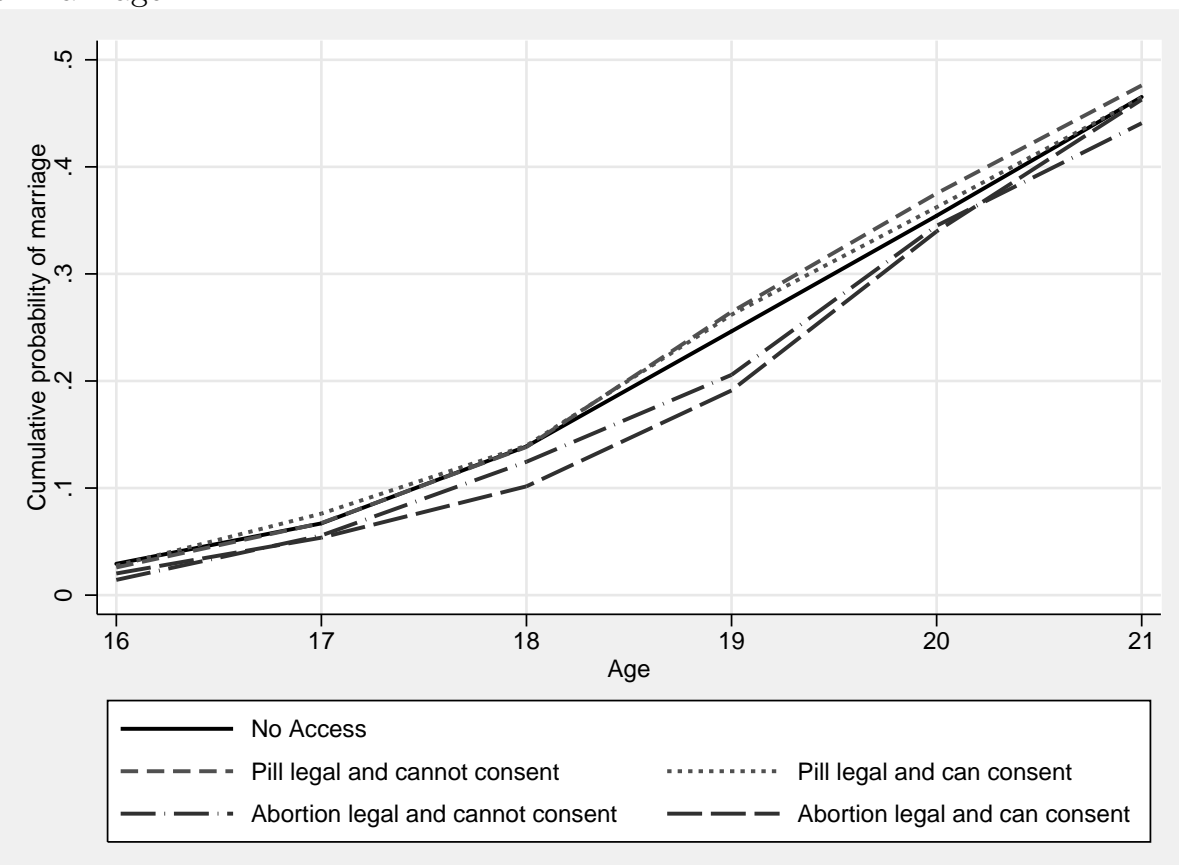

Average adjusted predicted cumulative probabilities of having married. Estimates are based on separate linear probability models of having married prior to each year of age from 16 through 21. Control variables include race and ethnicity, draft deferment policy, minimum age to consent to marriage, state fixed effects, year of birth cohort fixed effects, and state*cohort linear time trends. Data: CPS Fertility Supplements, 1979-1995. Sample: Women born between 1935 and 1958 who were aged $22+$ at the time of observation $(n=266,054)$. Sampling weights are applied. 
Figure 4: Estimated effects of reproductive control on the cumulative probability of shotgun marriage

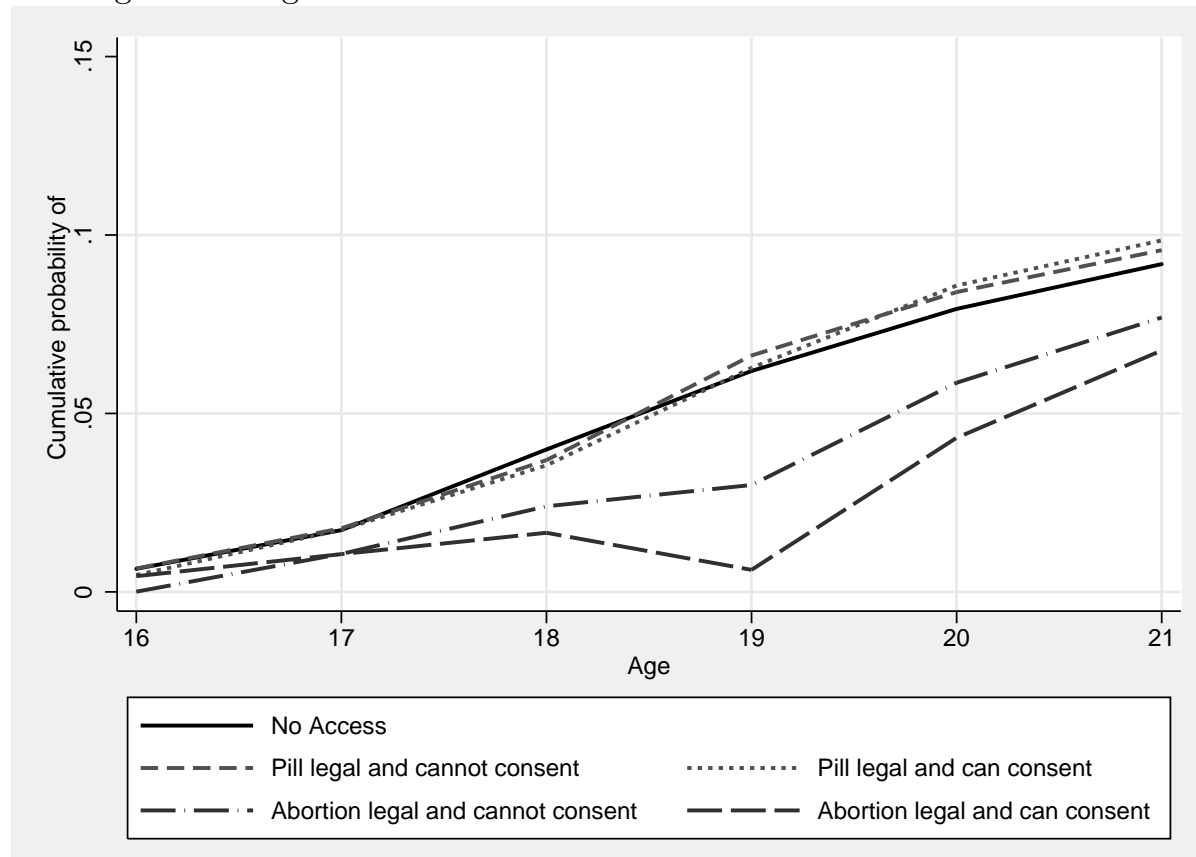

Average adjusted predicted cumulative probabilities of having had a "shotgun marriage," which is defined as a first marriage followed in less than eight months by a first birth. Estimates are based on separate linear probability models of having had a shotgun marriage prior to each year of age from 16 through 21 . Control variables include race and ethnicity, draft deferment policy, minimum age to consent to marriage, state fixed effects, year of birth cohort fixed effects, and state*cohort linear time trends. Data: CPS Fertility Supplements, 1979-1995. Sample: Women born between 1935 and 1958 who were aged 22+ at the time of observation $(\mathrm{n}=266,054)$. Sampling weights are applied. 
Figure 5: Fraction of women who had engaged in sexual intercourse prior to ages $15-24$, by year of birth

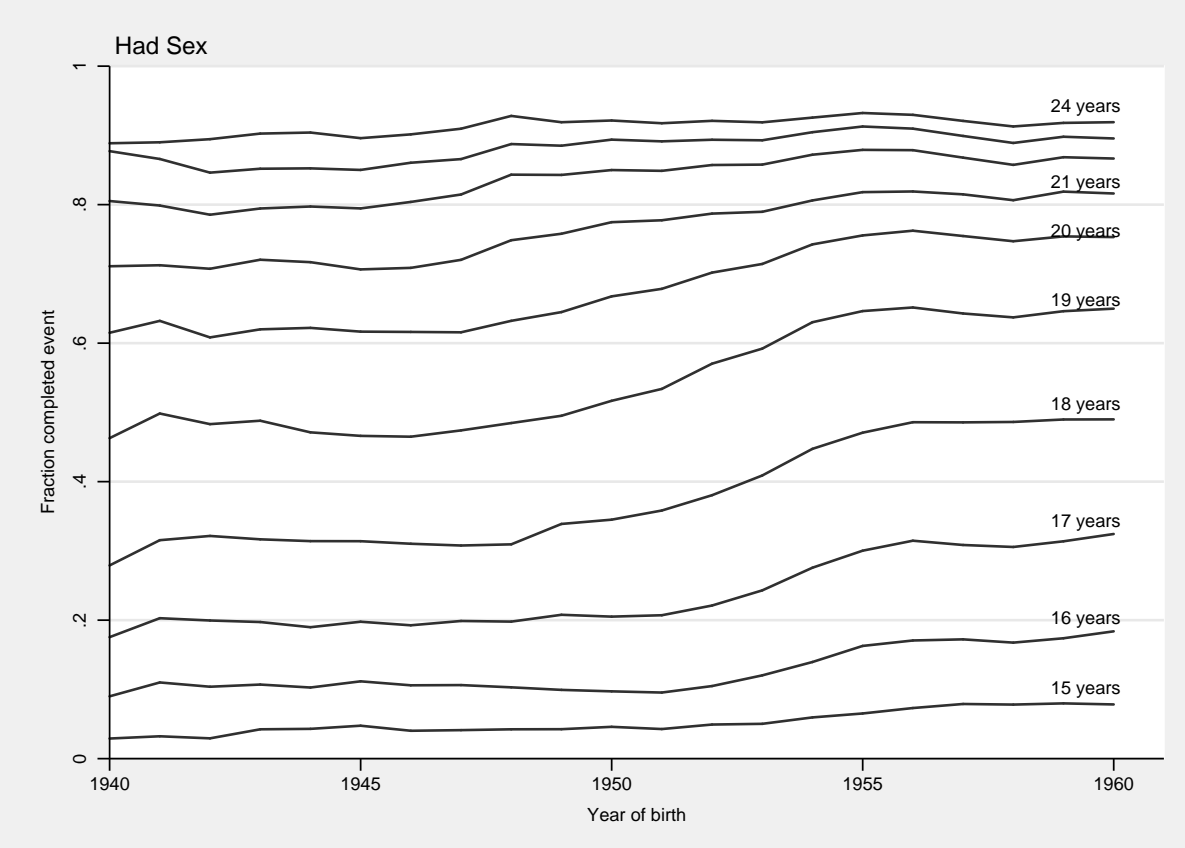

The cumulative probability of having engaged in sexual intercourse is calculated using the National Survey of Family Growth, Cycle 3 (1982), Cycle 4 (1988), and Cycle 5 (1995). Sample: Women born between 1940 and 1960, who were aged 24+ at the time of observation $(\mathrm{n}=14,943)$. Because of the small samples sizes, the reported fractions are smoothed using three-year moving averages. Sampling weights are applied. 
Figure 6: Fraction of women who had received family planning services prior to ages $15-24$, by year of birth

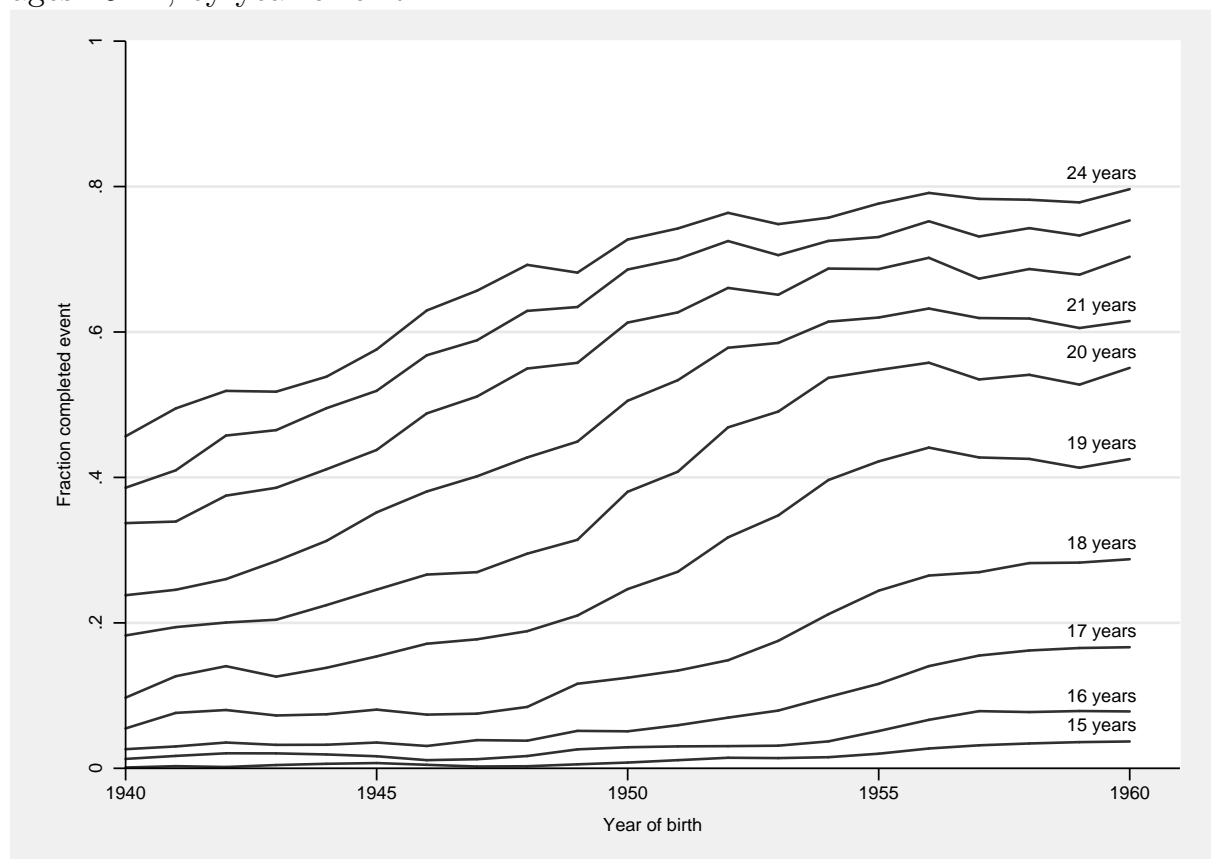

Three-year moving averages of the the fraction of women who recall having received family planning services prior to the indicated age. Source: Author's calculations using National Survey of Family Growth, Cycle 3 (1982) and Cycle 4 (1988). Sample: Women born between 1939 and 1961 who were aged 24 and over at time of observation $(n=11,084)$. 
Figure 7: Use of contraception at first sexual intercourse

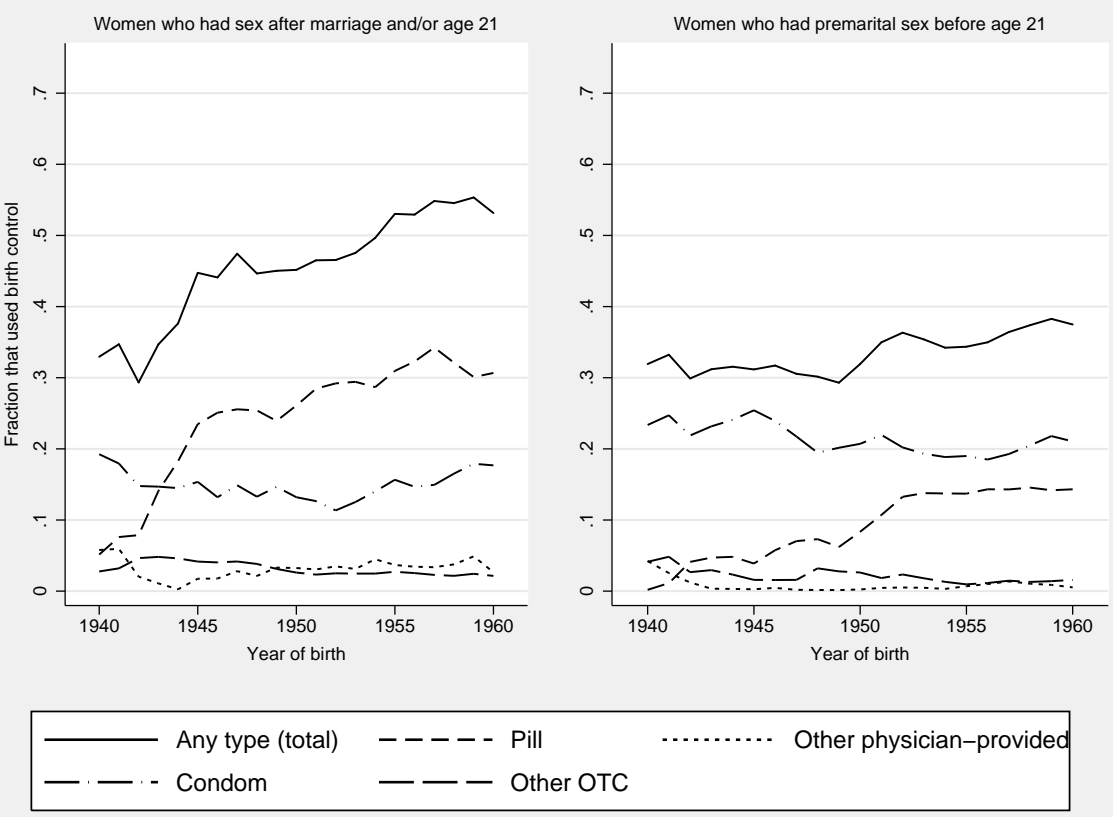

Three-year moving averages of the fraction of women who reported using various form of birth control at first voluntary sexual intercourse. Birth control methods are the contraceptive pill, other physician-provided methods (diaphragm, IUD, sterilization), condom, and other over-the-counter methods(foam, jelly, suppository, all if used without a condom). Source: National Survey of Family Growth, Cycle 3 (1982), Cycle 4 (1988), and Cycle 5 (1995). Sample: Women born between 1939 and 1961, who were aged 24+ and had engaged in sexual intercourse at the time of observation. The sample is divided into women whose first sexual intercourse either occurred within a month of their first marriage or after the age of 21 (Panel $1, \mathrm{n}=4,282$ ) and women whose first sexual intercourse was premarital and prior to the age of 21(Panel 2, $\mathrm{n}=10,430)$. 
Figure 8: Fraction of women who report they had an abortion prior to ages 18 and 21

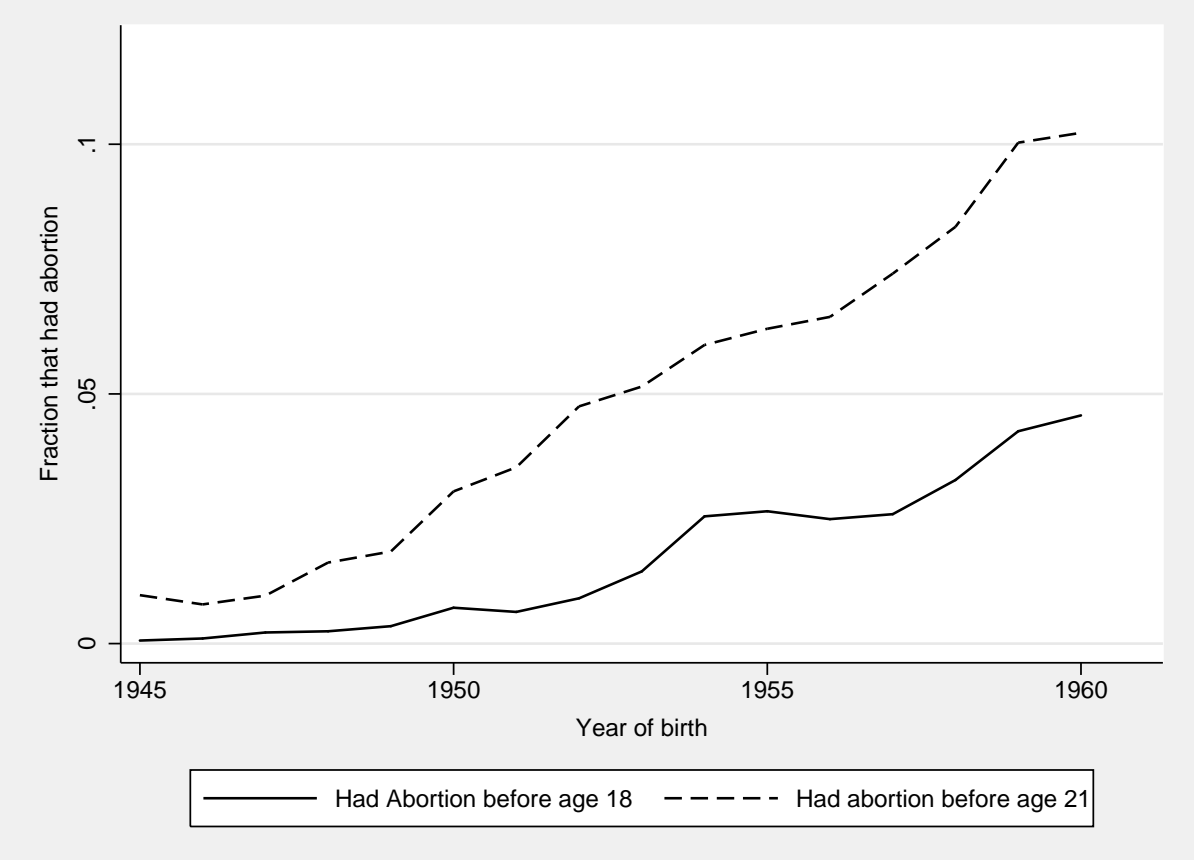

Three-year moving averages of the fraction of women who reported having had an abortion prior to ages 18 and 21. Source: National Survey of Family Growth, Cycle 4 (1988). Sample: Women born between 1939 and 1961, who were aged $24(\mathrm{n}=5,512)$. 


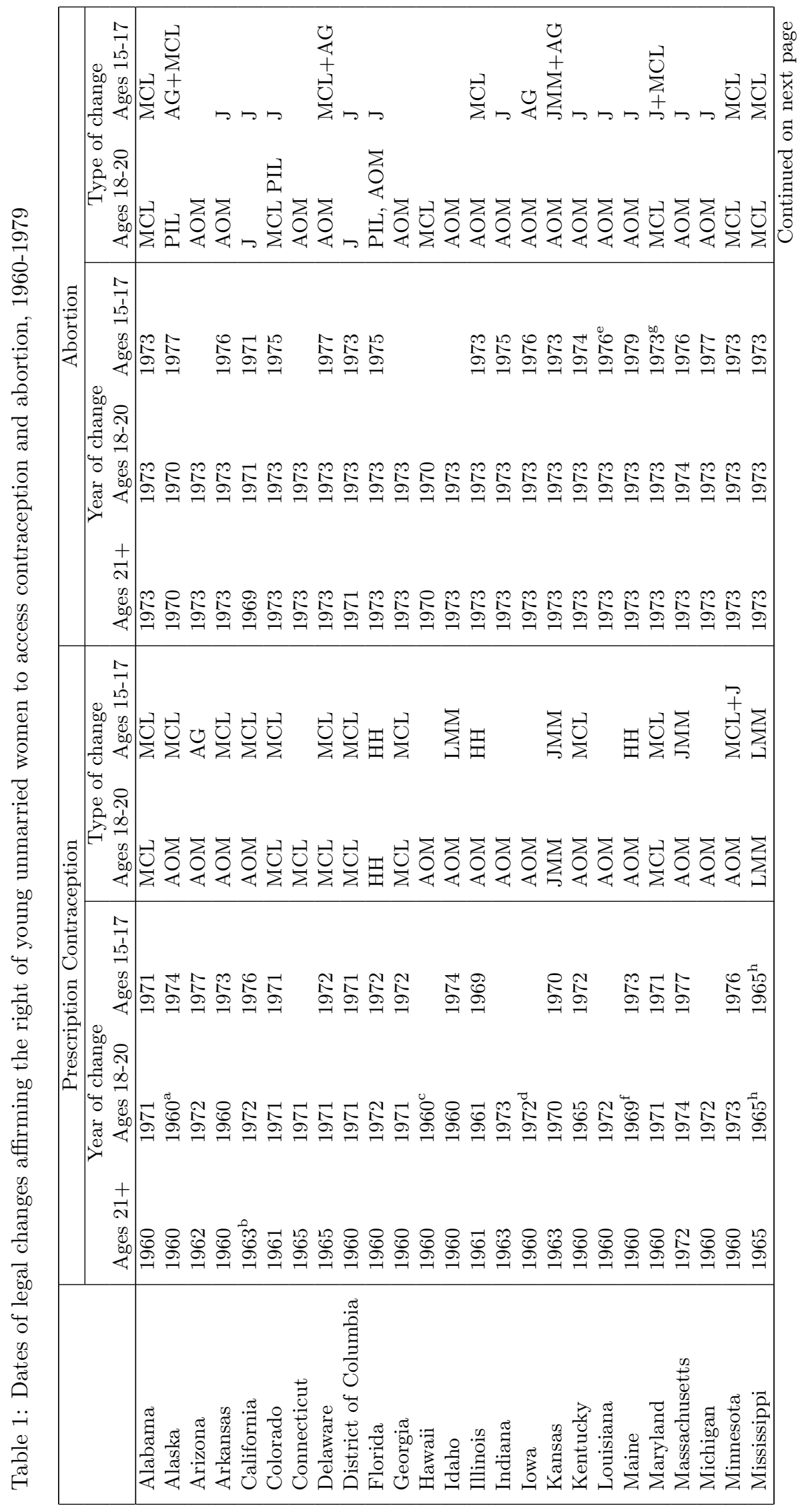




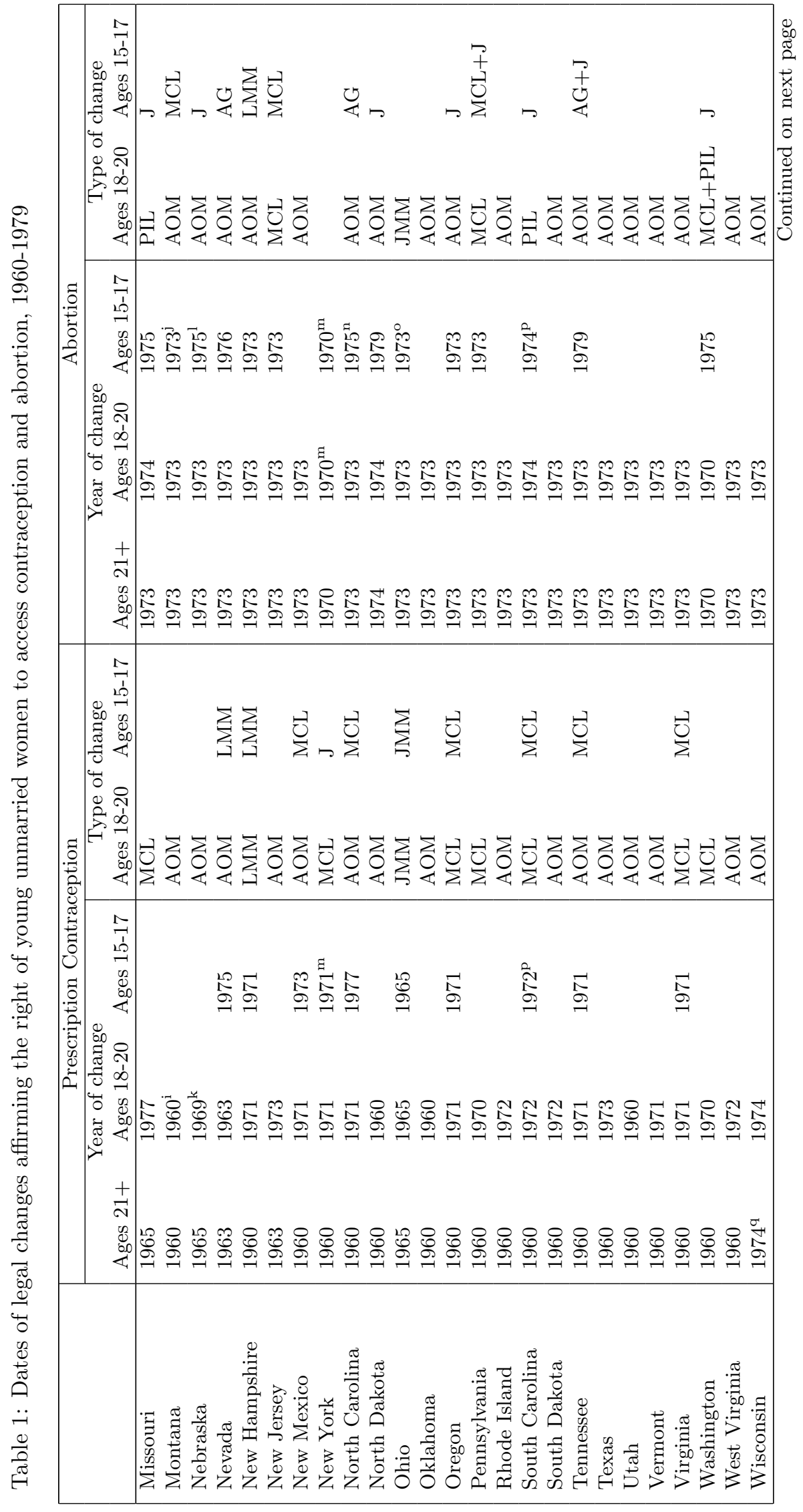




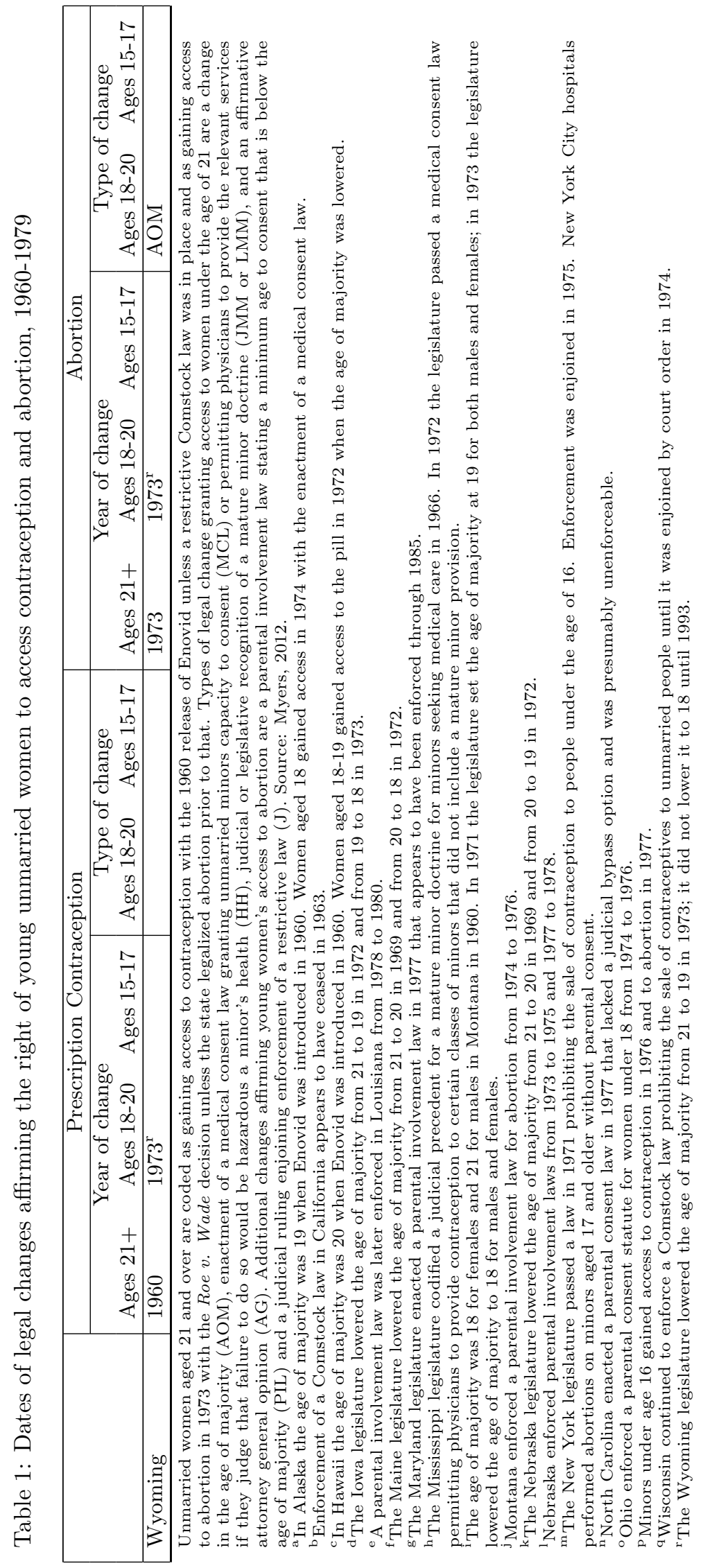


Table 2: Estimated effects of reproductive control on the probabilities of giving birth and marrying prior to age 19

\begin{tabular}{|c|c|c|c|c|}
\hline & Model 1 & Model 2 & Model 3 & Model 4 \\
\hline \multicolumn{5}{|l|}{$\operatorname{Pr}($ birth $<19)$} \\
\hline Pill legal & & $\begin{array}{l}-0.0052 \\
(0.0062)\end{array}$ & $\begin{array}{l}-0.0036 \\
(0.0059)\end{array}$ & $\begin{array}{l}-0.0030 \\
(0.0058)\end{array}$ \\
\hline Consent pill & $\begin{array}{l}-0.0019 \\
(0.0094)\end{array}$ & $\begin{array}{l}-0.0069 \\
(0.0116)\end{array}$ & $\begin{array}{l}-0.0067 \\
(0.0114)\end{array}$ & $\begin{array}{l}-0.0052 \\
(0.0102)\end{array}$ \\
\hline Abortion legal & & & $\begin{array}{l}-0.0108 \\
(0.0079)\end{array}$ & $\begin{array}{l}-0.0284^{* * *} \\
(0.0070)\end{array}$ \\
\hline Consent abortion & & & $\begin{array}{l}-0.0258^{* * *} \\
(0.0054)\end{array}$ & $\begin{array}{l}-0.0502^{* * *} \\
(0.0090)\end{array}$ \\
\hline \multicolumn{5}{|l|}{$\operatorname{Pr}($ marriage $<19)$} \\
\hline Pill legal & & $\begin{array}{c}0.0101 \\
(0.0104)\end{array}$ & $\begin{array}{c}0.0131 \\
(0.0099)\end{array}$ & $\begin{array}{c}0.0181^{*} \\
(0.0105)\end{array}$ \\
\hline Consent pill & $\begin{array}{c}0.0054 \\
(0.0135)\end{array}$ & $\begin{array}{c}0.0149 \\
(0.0176)\end{array}$ & $\begin{array}{c}0.0159 \\
(0.0171)\end{array}$ & $\begin{array}{c}0.0156 \\
(0.0190)\end{array}$ \\
\hline Abortion legal & & & $\begin{array}{l}-0.0207^{*} \\
(0.0105)\end{array}$ & $\begin{array}{l}-0.0407^{* * *} \\
(0.0132)\end{array}$ \\
\hline Consent abortion & & & $\begin{array}{l}-0.0459^{* * *} \\
(0.0167)\end{array}$ & $\begin{array}{l}-0.0552^{* * *} \\
(0.0167)\end{array}$ \\
\hline \multicolumn{5}{|l|}{$\operatorname{Pr}($ shotgun marriage $<19)$} \\
\hline Pill legal & & $\begin{array}{c}0.0056 \\
(0.0074)\end{array}$ & $\begin{array}{c}0.0082 \\
(0.0058)\end{array}$ & $\begin{array}{c}0.0043 \\
(0.0056)\end{array}$ \\
\hline Consent pill & $\begin{array}{l}-0.0038 \\
(0.0056)\end{array}$ & $\begin{array}{c}0.0015 \\
(0.0074)\end{array}$ & $\begin{array}{c}0.0023 \\
(0.0069)\end{array}$ & $\begin{array}{c}0.0009 \\
(0.0067)\end{array}$ \\
\hline Abortion legal & & & $\begin{array}{l}-0.0178^{* * *} \\
(0.0055)\end{array}$ & $\begin{array}{l}-0.0320^{* * *} \\
(0.0066)\end{array}$ \\
\hline Consent abortion & & & $\begin{array}{l}-0.0398^{* * *} \\
(0.0059)\end{array}$ & $\begin{array}{l}-0.0557^{* * *} \\
(0.0089)\end{array}$ \\
\hline Controls for race and ethnicity & yes & yes & yes & yes \\
\hline State and cohort fixed effects & yes & yes & yes & yes \\
\hline State linear time trends & no & no & no & yes \\
\hline
\end{tabular}

The table reports coefficients and standard errors from linear probability models in which the dependent variable indicates whether a woman had given birth, married or had a shotgun marriage prior to age 19. Pill legal and Abortion legal measure the proportion of years from ages 14 to 17 (birth) or 14 to 18 (marriage) in which the pill or abortion were legally available to adults but not to young women. Consent pill and Consent abortion measure the proportion of prior years in which the pill or abortion were legally available to adults and state law granted young unmarried women capacity to consent to them. "Shotgun marriage" is defined as a first marriage that was followed within eight months by a first birth. Standard errors are clustered at the state level. Data: CPS Fertility Supplements, 1979-1995. Sample: Women born from 1935 to 1958 who were aged $22+$ at the time of observation $(\mathrm{n}=266,054) .{ }^{*} p<0.10{ }^{* *} p<0.05{ }^{* * *} p<0.01$. 


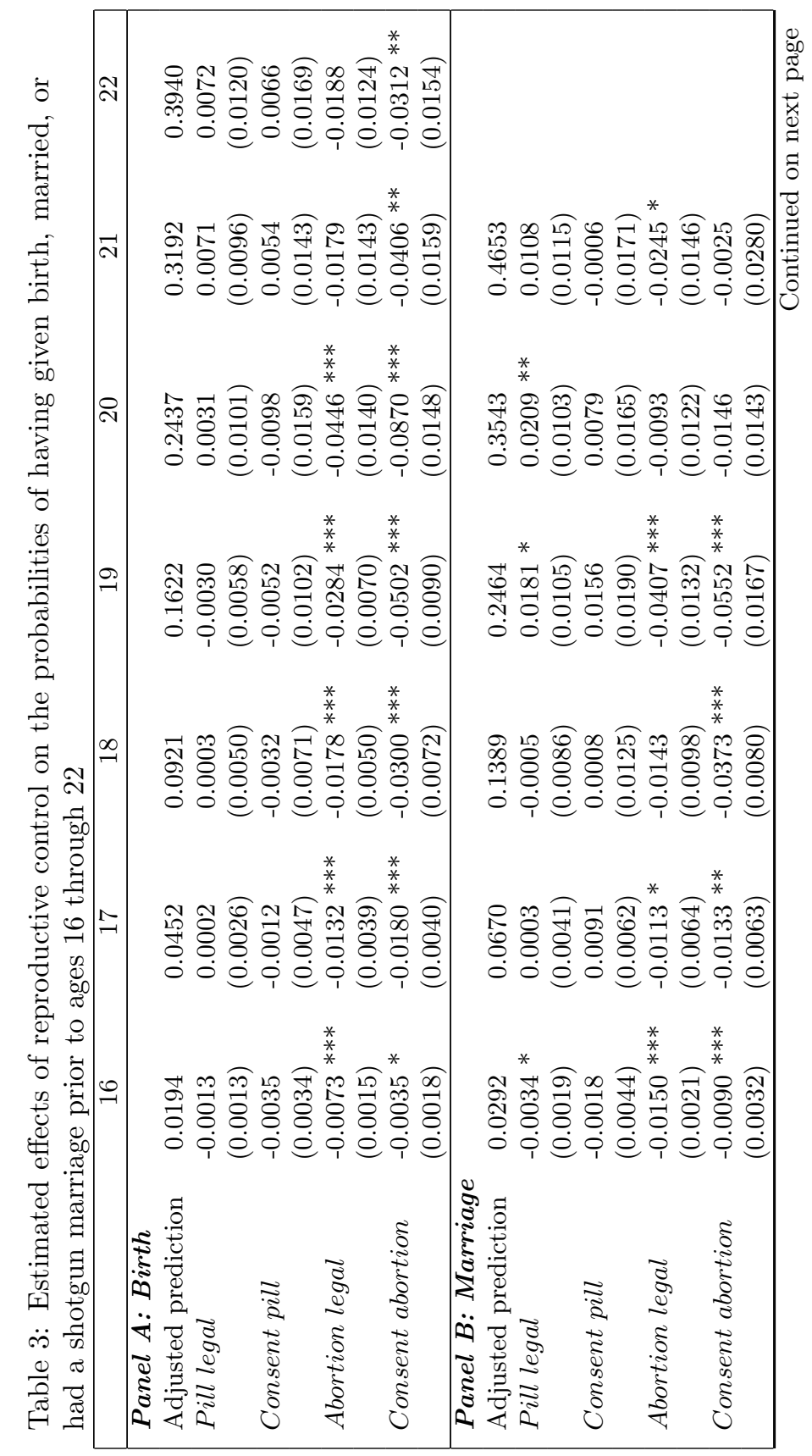




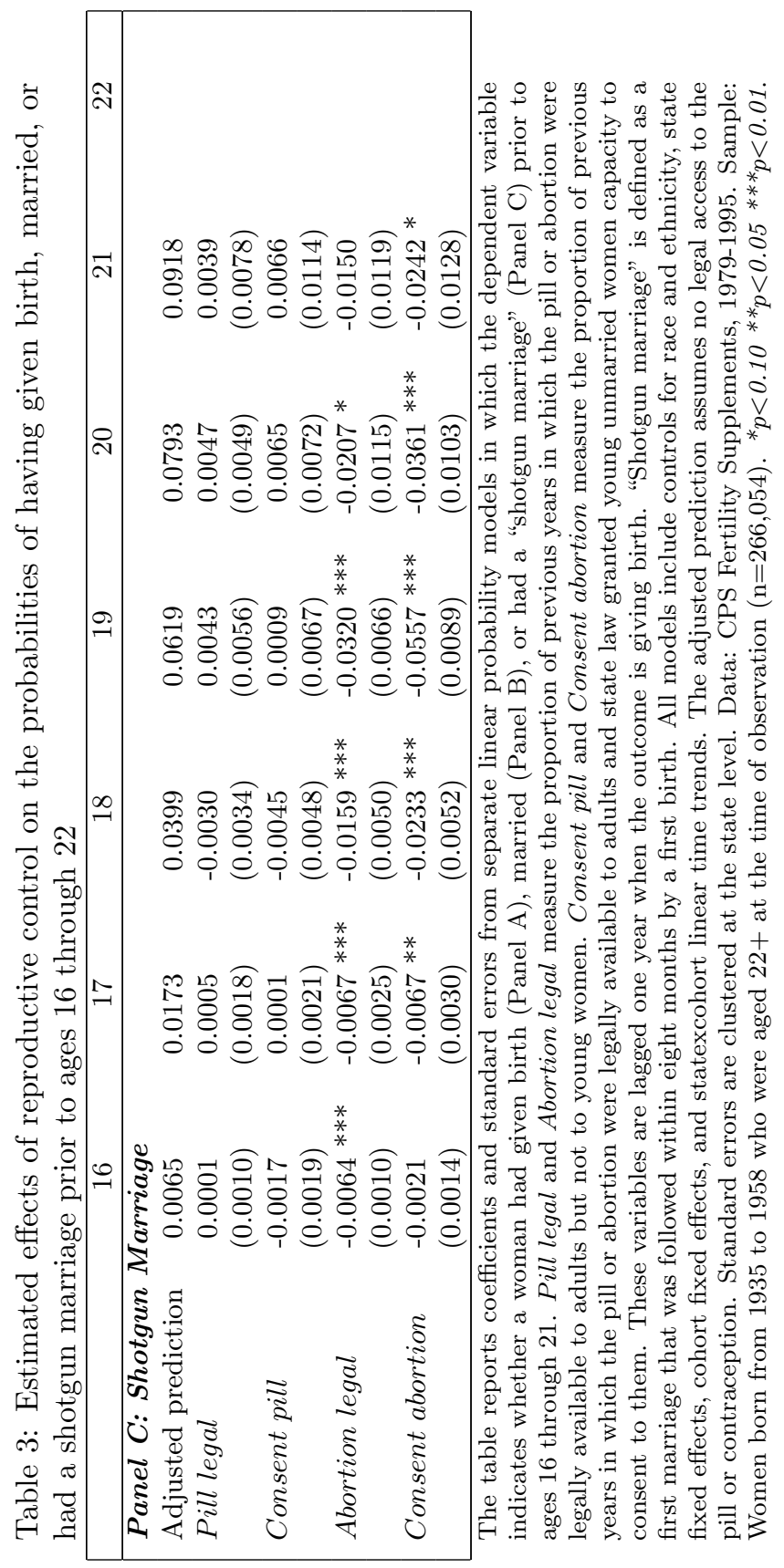


Table 4: Estimated effects of reproductive control on the probabilities of giving birth and marrying prior to age 19 for different sub-samples of the population

\begin{tabular}{|c|c|c|c|c|c|}
\hline & $\begin{array}{c}\text { Full } \\
\text { sample }\end{array}$ & Whites & Blacks & $\begin{array}{c}\text { Omits } \\
\text { reform } \\
\text { states }\end{array}$ & $\begin{array}{c}\text { Limited } \\
\text { interstate } \\
\text { travel } \\
\text { states }\end{array}$ \\
\hline \multicolumn{6}{|l|}{$\operatorname{Pr}($ birth $<19)$} \\
\hline Adjusted prediction & 0.1622 & 0.1371 & 0.3219 & 0.1616 & \\
\hline Pill legal & $\begin{array}{l}-0.0030 \\
(0.0058)\end{array}$ & $\begin{array}{l}-0.0086 \\
(0.0056)\end{array}$ & $\begin{array}{c}0.0181 \\
(0.0312)\end{array}$ & $\begin{array}{l}-0.0077 \\
(0.0063)\end{array}$ & $\begin{array}{l}-0.0115 \\
(0.0075)\end{array}$ \\
\hline Consent pill & $\begin{array}{l}-0.0052 \\
(0.0102)\end{array}$ & $\begin{array}{l}-0.0126 \\
(0.0090)\end{array}$ & $\begin{array}{c}0.0308 \\
(0.0463)\end{array}$ & $\begin{array}{l}-0.0018 \\
(0.0113)\end{array}$ & $\begin{array}{l}-0.0237^{* *} \\
(0.0112)\end{array}$ \\
\hline Abortion legal & $\begin{array}{l}-0.0284^{* * *} \\
(0.0070)\end{array}$ & $\begin{array}{l}-0.0162^{* *} \\
(0.0078)\end{array}$ & $\begin{array}{l}-0.0863^{* *} \\
(0.0347)\end{array}$ & $\begin{array}{l}-0.0398^{* * *} \\
(0.0111)\end{array}$ & $\begin{array}{l}-0.0367^{* * *} \\
(0.0071)\end{array}$ \\
\hline Consent abortion & $\begin{array}{l}-0.0502^{* * *} \\
(0.0090)\end{array}$ & $\begin{array}{l}-0.0363^{* * *} \\
(0.0091)\end{array}$ & $\begin{array}{l}-0.1441^{* * *} \\
(0.0445)\end{array}$ & $\begin{array}{l}-0.0651^{* * *} \\
(0.0124)\end{array}$ & $\begin{array}{l}-0.0638^{* * *} \\
(0.0085)\end{array}$ \\
\hline \multicolumn{6}{|l|}{$\operatorname{Pr}($ marriage $<19)$} \\
\hline Adjusted prediction & 0.2464 & 0.2590 & 0.1951 & 0.2488 & \\
\hline Pill legal & $\begin{array}{c}0.0181^{*} \\
(0.0105)\end{array}$ & $\begin{array}{c}0.0103 \\
(0.0087)\end{array}$ & $\begin{array}{c}0.0525 \\
(0.0386)\end{array}$ & $\begin{array}{c}0.0083 \\
(0.0120)\end{array}$ & $\begin{array}{c}0.0220^{*} \\
(0.0116)\end{array}$ \\
\hline Consent pill & $\begin{array}{c}0.0156 \\
(0.0190)\end{array}$ & $\begin{array}{c}0.0063 \\
(0.0164)\end{array}$ & $\begin{array}{c}0.0602 \\
(0.0596)\end{array}$ & $\begin{array}{c}0.0187 \\
(0.0226)\end{array}$ & $\begin{array}{c}0.0110 \\
(0.0225)\end{array}$ \\
\hline Abortion legal & $\begin{array}{l}-0.0407^{* * *} \\
(0.0132)\end{array}$ & $\begin{array}{l}-0.0463^{* * *} \\
(0.0127)\end{array}$ & $\begin{array}{l}-0.039 \\
(0.0331)\end{array}$ & $\begin{array}{l}-0.0672^{* * *} \\
(0.0180)\end{array}$ & $\begin{array}{l}-0.0516^{* * *} \\
(0.0158)\end{array}$ \\
\hline Consent abortion & $\begin{array}{l}-0.0552^{* * *} \\
(0.0167)\end{array}$ & $\begin{array}{l}-0.0506^{* *} \\
(0.0202)\end{array}$ & $\begin{array}{l}-0.1194^{* *} \\
(0.0555)\end{array}$ & $\begin{array}{l}-0.0692^{* * *} \\
(0.0217)\end{array}$ & $\begin{array}{l}-0.0857^{* * *} \\
(0.0184)\end{array}$ \\
\hline \multicolumn{6}{|c|}{$\operatorname{Pr}($ shotgun marriage $<19)$} \\
\hline Adjusted prediction & 0.0619 & 0.0612 & 0.0815 & 0.0624 & \\
\hline Pill legal & $\begin{array}{c}0.0043 \\
(0.0056)\end{array}$ & $\begin{array}{c}0.0077 \\
(0.0067)\end{array}$ & $\begin{array}{l}-0.023 \\
(0.0181)\end{array}$ & $\begin{array}{c}0.0074 \\
(0.0053)\end{array}$ & $\begin{array}{c}0.0022 \\
(0.0078)\end{array}$ \\
\hline Consent pill & $\begin{array}{c}0.0009 \\
(0.0067)\end{array}$ & $\begin{array}{c}0.0035 \\
(0.0071)\end{array}$ & $\begin{array}{l}-0.0273 \\
(0.0182)\end{array}$ & $\begin{array}{c}0.0078 \\
(0.0081)\end{array}$ & $\begin{array}{l}-0.0056 \\
(0.0106)\end{array}$ \\
\hline Abortion legal & $\begin{array}{l}-0.0320^{* * *} \\
(0.0066)\end{array}$ & $\begin{array}{l}-0.0389^{* * *} \\
(0.0074)\end{array}$ & $\begin{array}{l}-0.0195 \\
(0.0172)\end{array}$ & $\begin{array}{l}-0.0381^{* *} \\
(0.0140)\end{array}$ & $\begin{array}{l}-0.0330^{* * *} \\
(0.0086)\end{array}$ \\
\hline Consent abortion & $\begin{array}{l}-0.0557^{* * *} \\
(0.0089)\end{array}$ & $\begin{array}{l}-0.0592^{* * *} \\
(0.0142)\end{array}$ & $\begin{array}{l}-0.0438 \\
(0.0301)\end{array}$ & $\begin{array}{l}-0.0579^{* * *} \\
(0.0191)\end{array}$ & $\begin{array}{l}-0.0626^{* * *} \\
(0.0119)\end{array}$ \\
\hline $\mathrm{n}$ & 266,054 & 211,227 & 28,485 & 188,094 & 164,296 \\
\hline
\end{tabular}

The table reports coefficients and standard errors from linear probability models in which the dependent variable indicates whether a woman had given birth, married or had a shotgun marriage prior to age 19. All models include state and cohort fixed effects, and state-cohort linear time trends; models in the first and last columns include controls for race. "Shotgun marriage" is defined as a first marriage that was followed within eight months by a first birth. The adjusted prediction assumes no legal access to the pill or contraception. The "limited interstate travel" sample includes only repeal states and states that are more than 500 miles from repeal states where the distance is measured between population centers using the 2000 U.S. Census. Standard errors are clustered at the state level. Data: CPS Fertility Supplements, 1979-1995. Sample: Women born from 1935 to 1958 who were aged $22+$ at the time of observation. ${ }^{*} p<0.10{ }^{* *} p<0.05$ ${ }^{* * *} p<0.01$. 


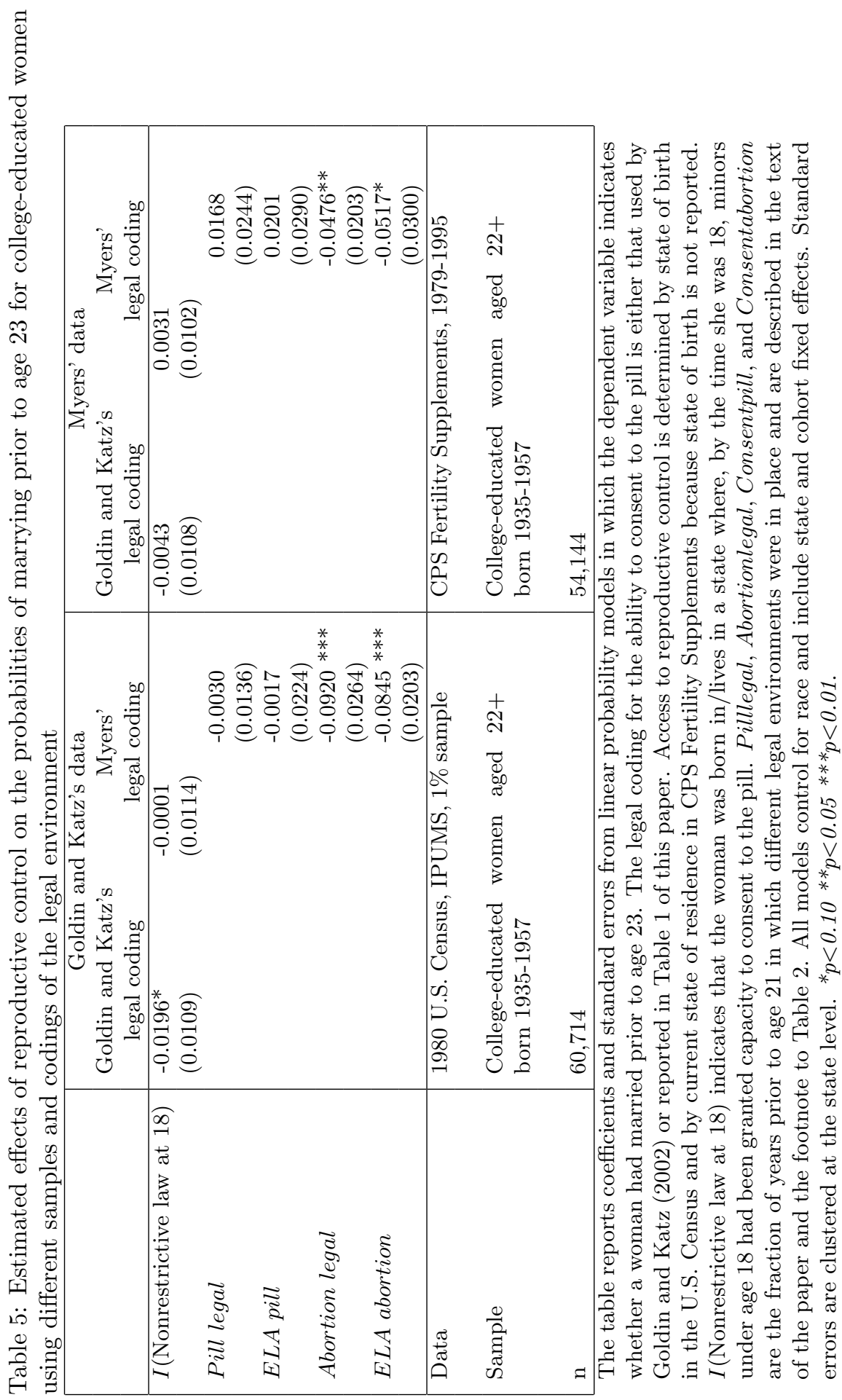




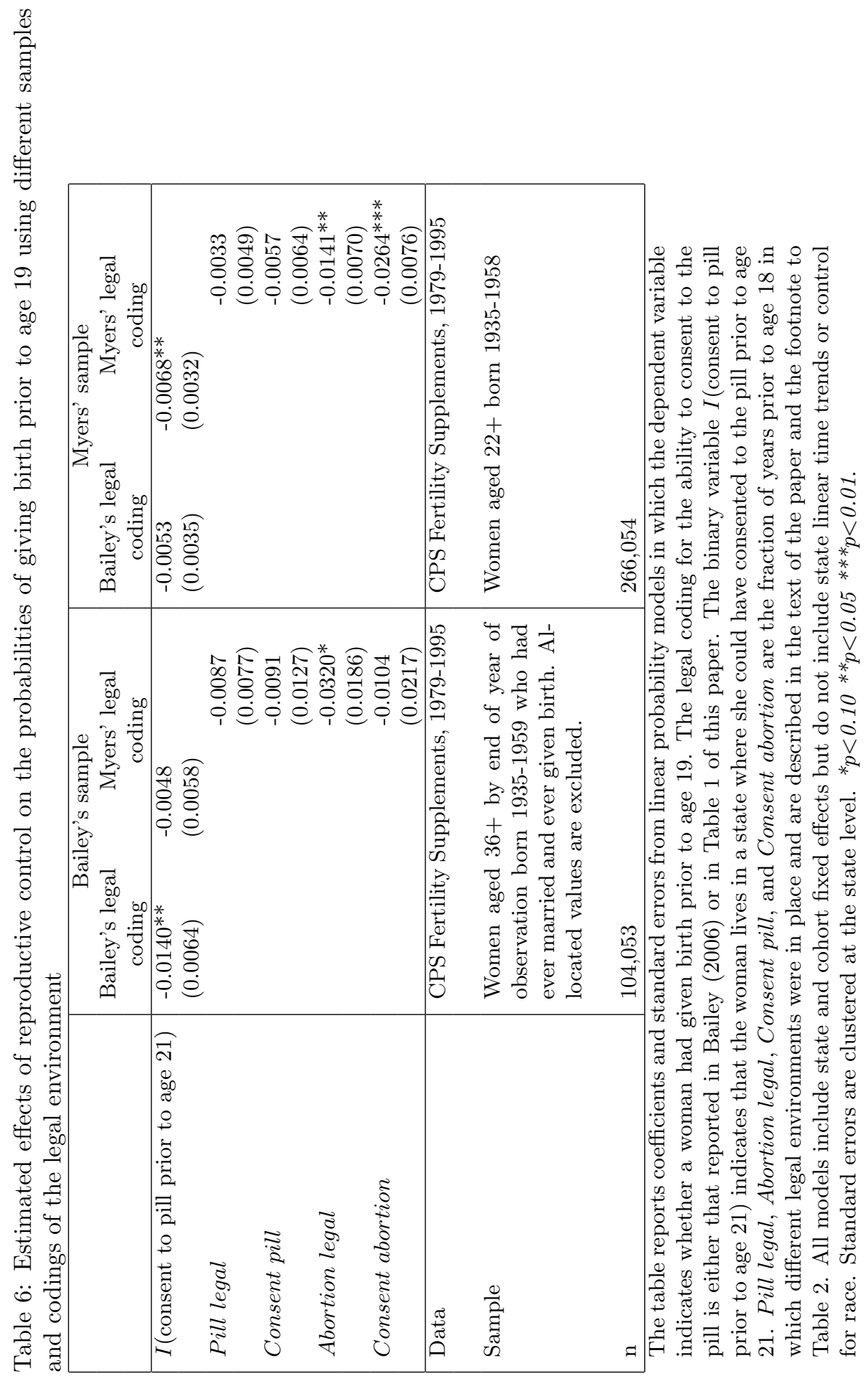


Appendix A: Tables reconciling differences in the legal coding reproduced from Myers (2012) 


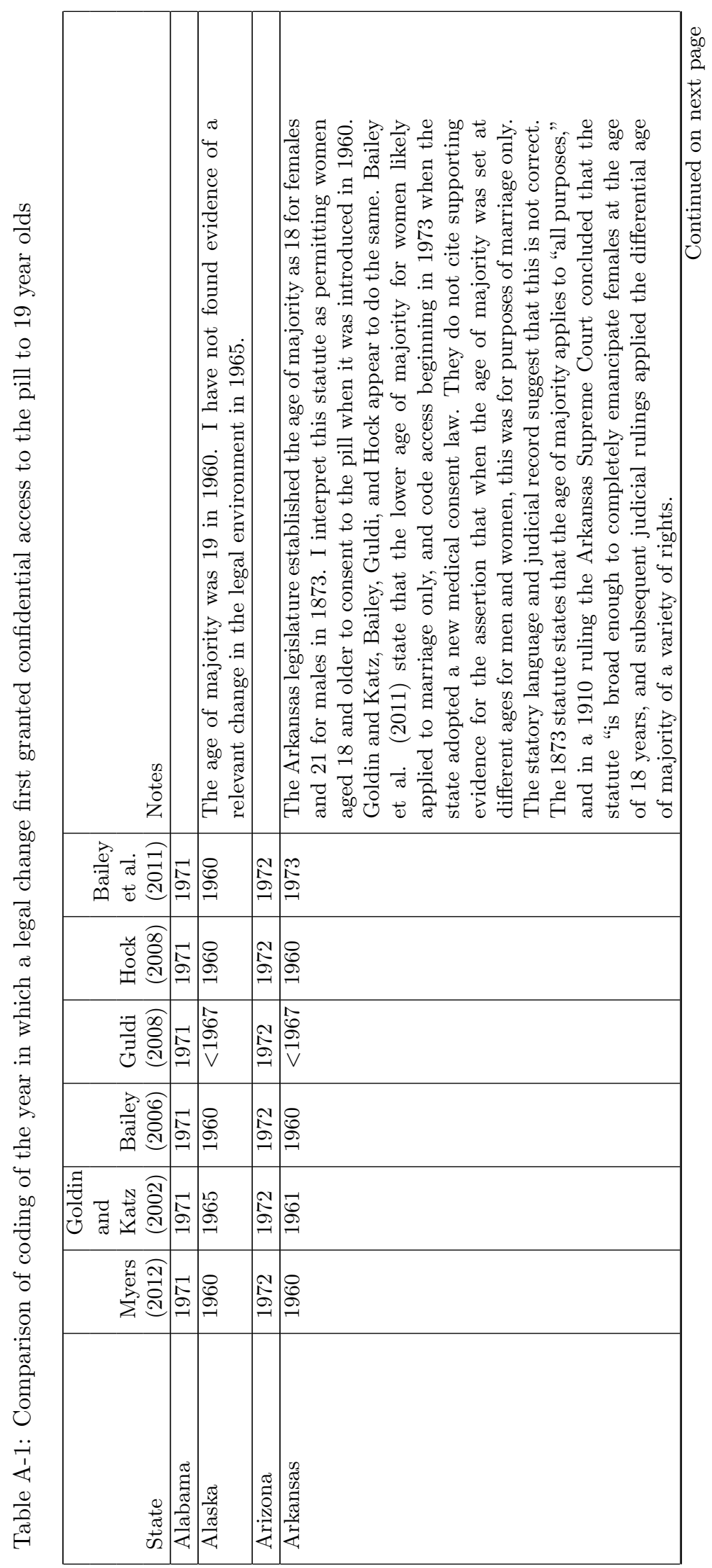




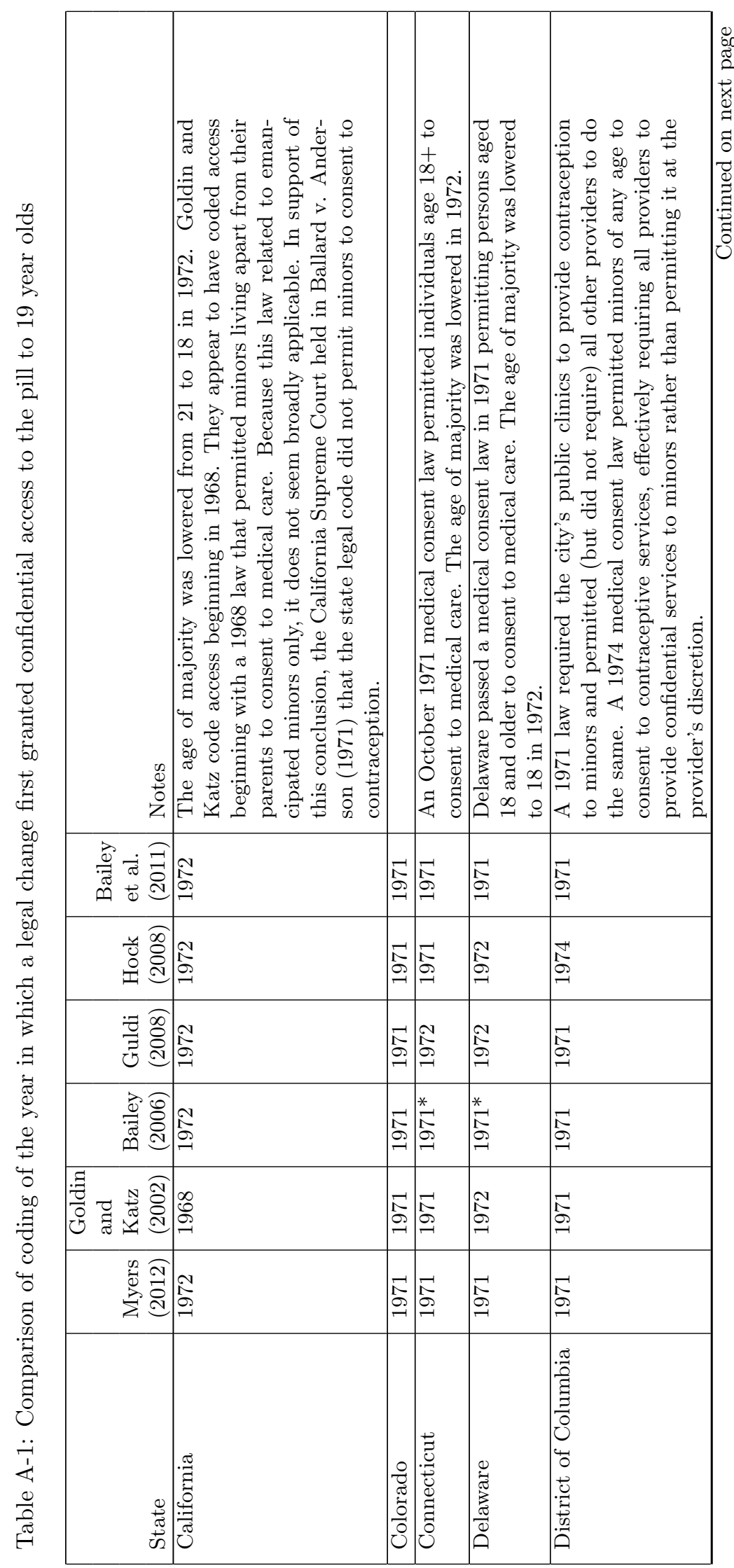

A-3 


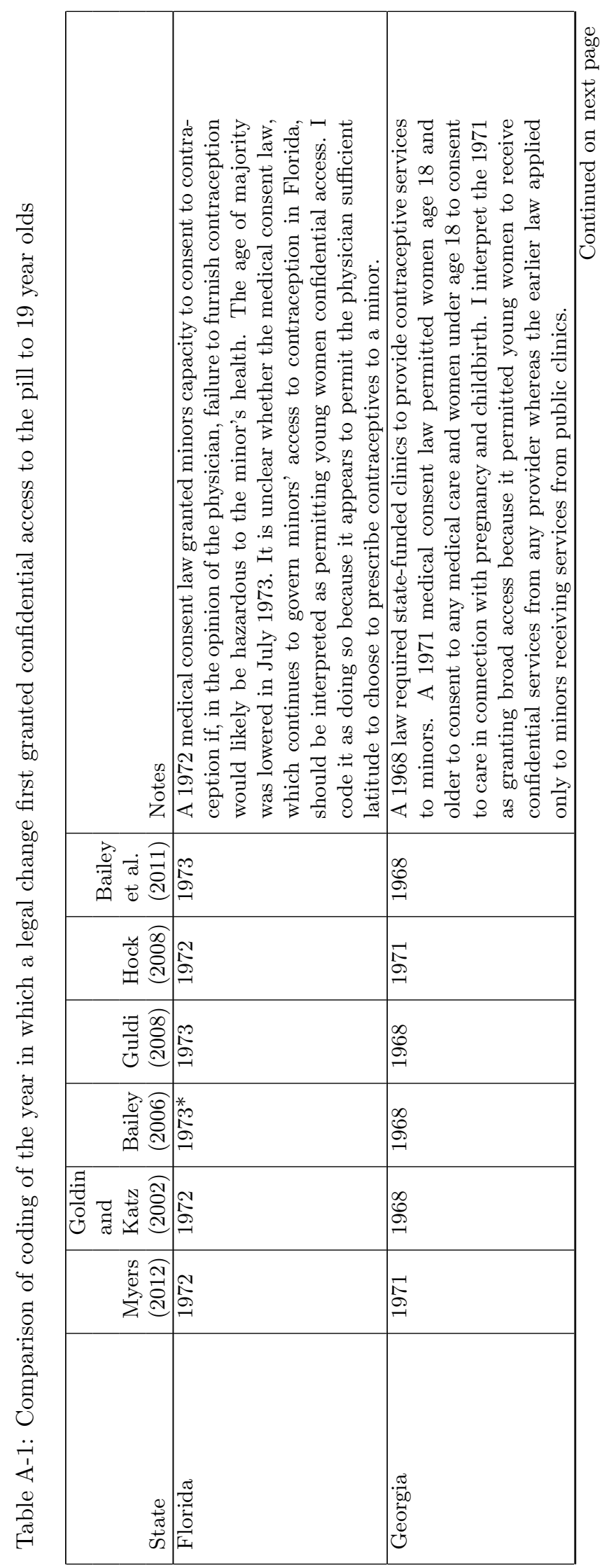




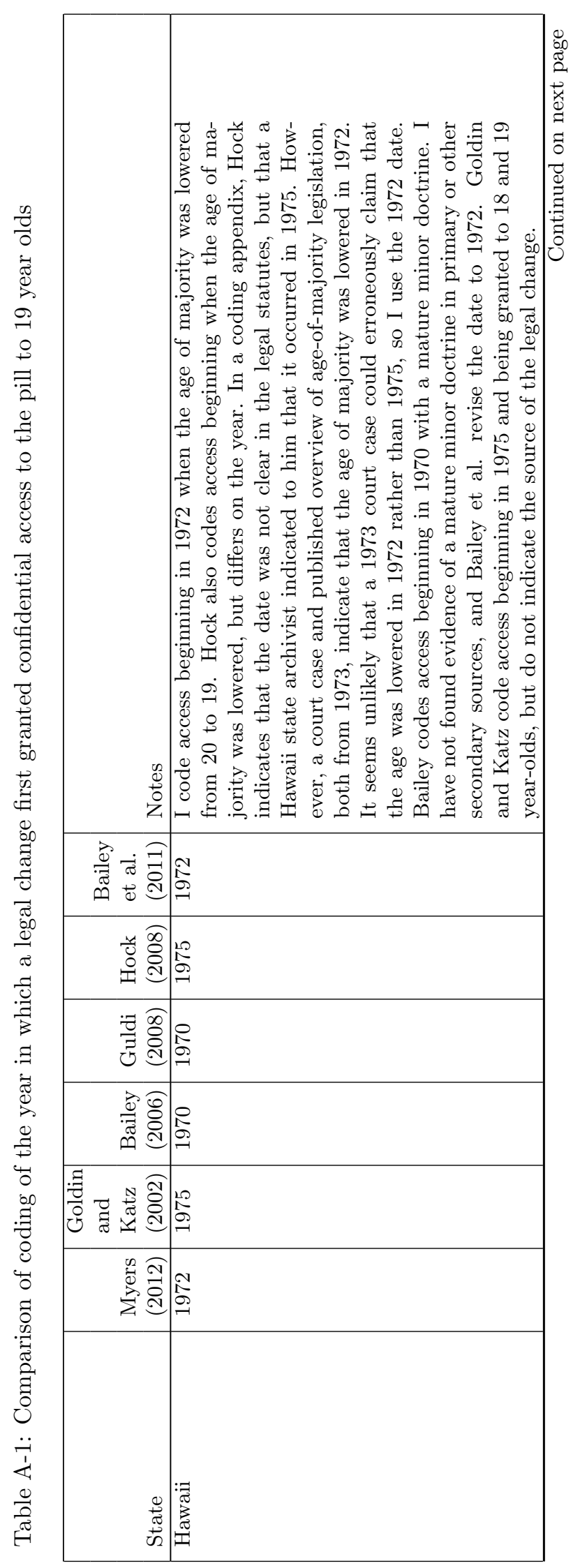

A-5 


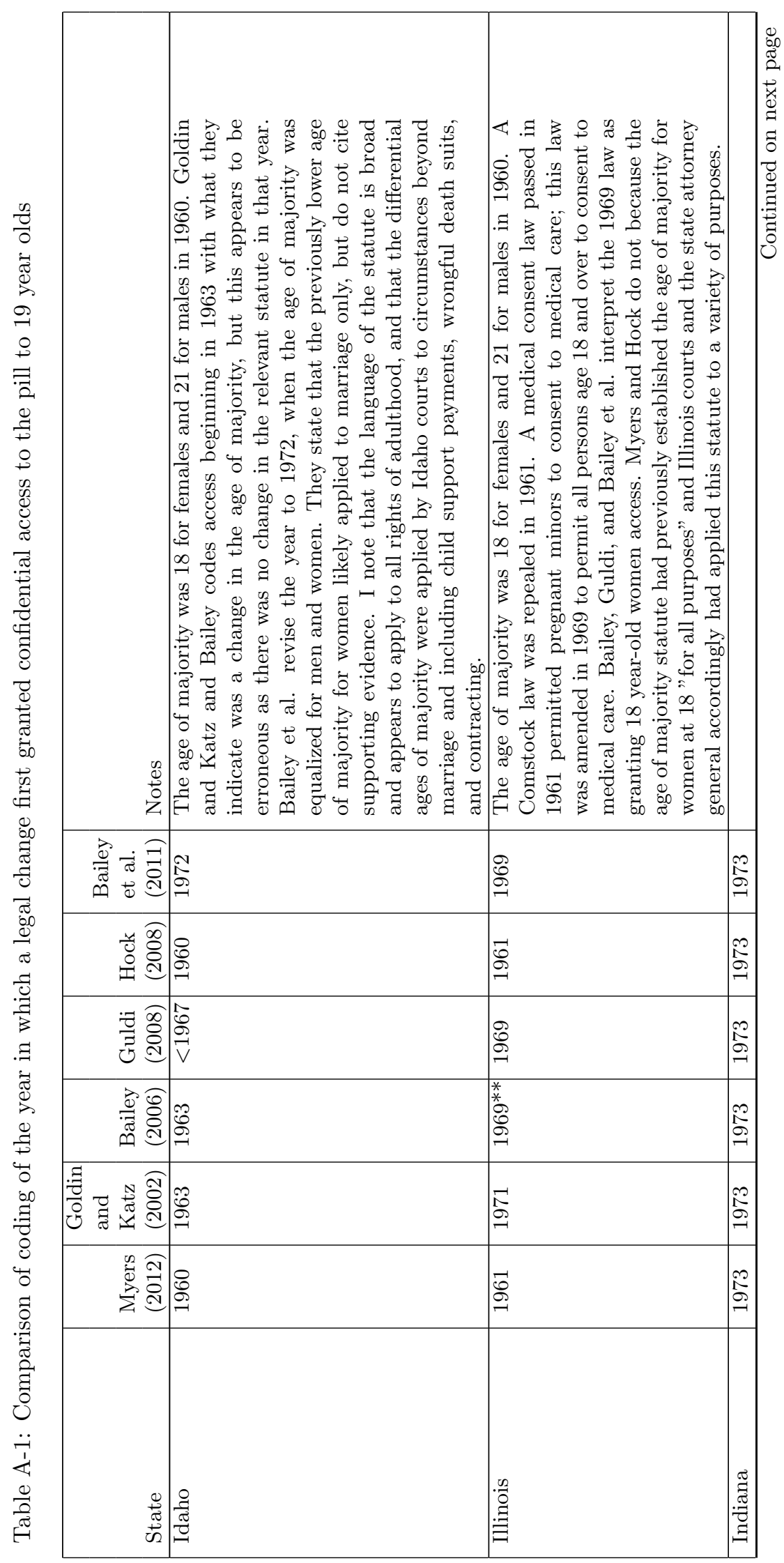

A- 6 


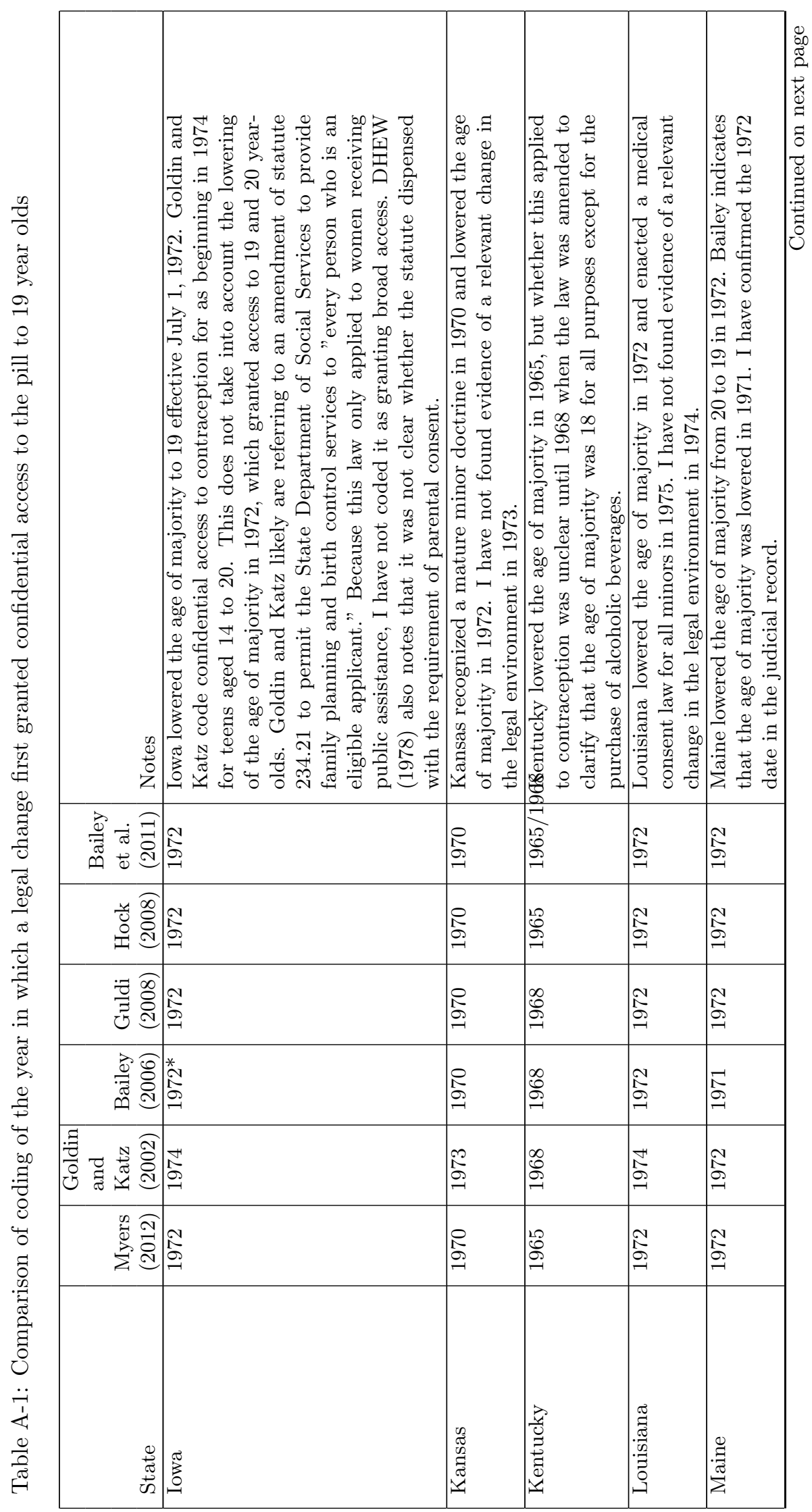

A-7 


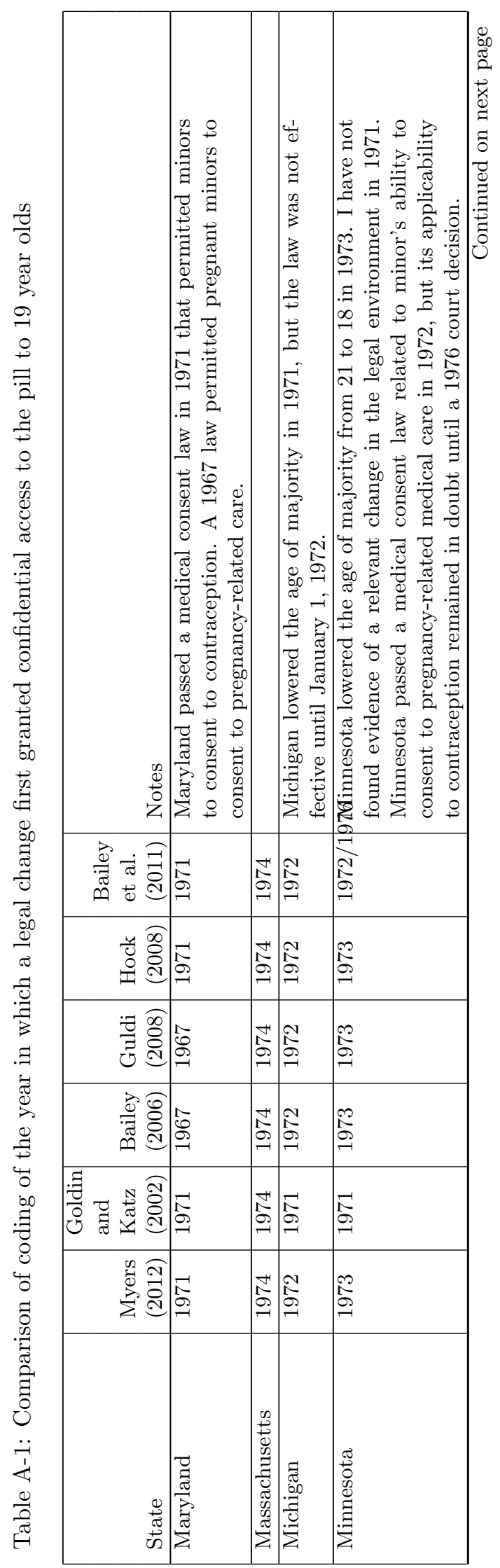

A-8 


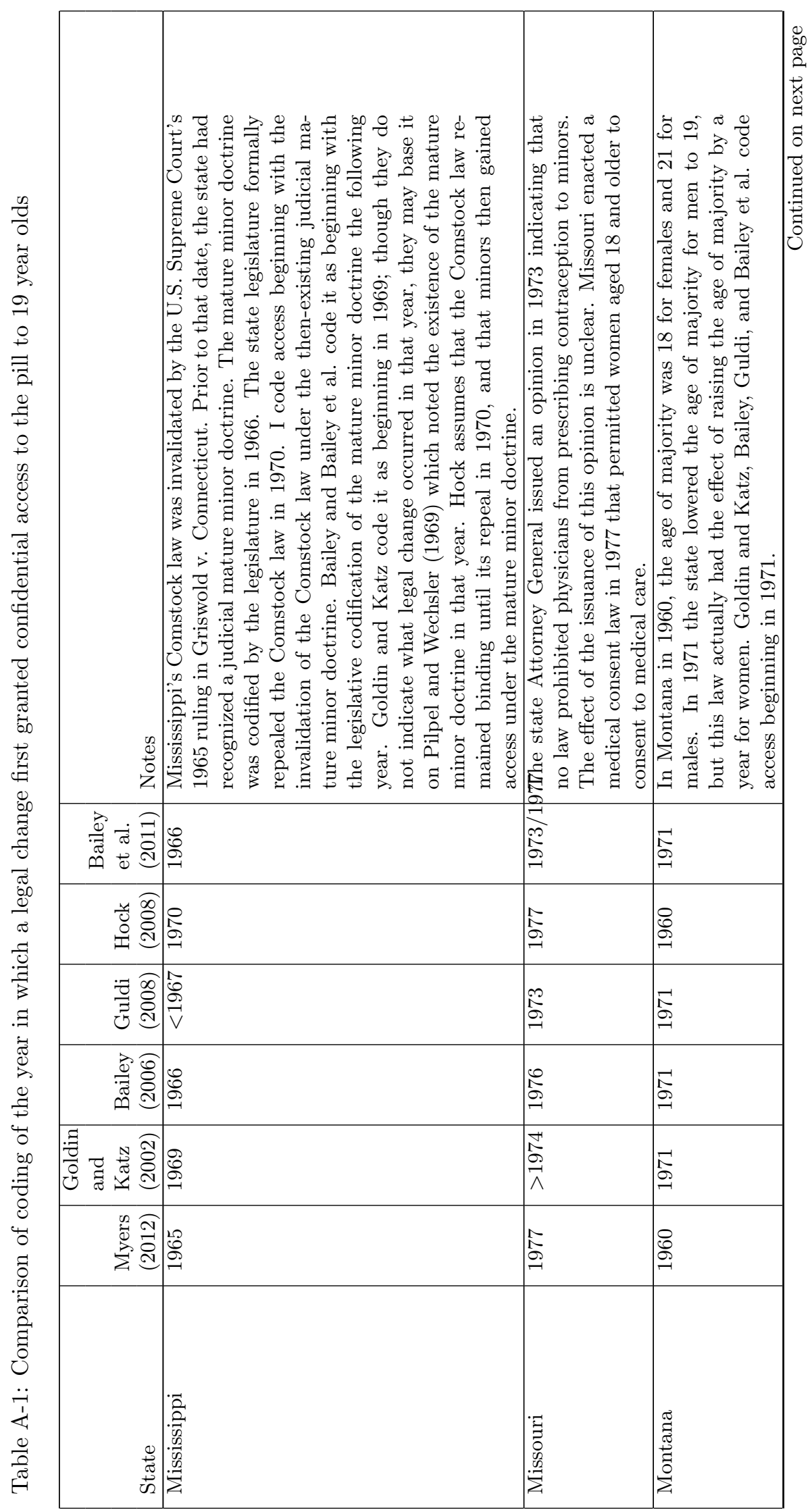




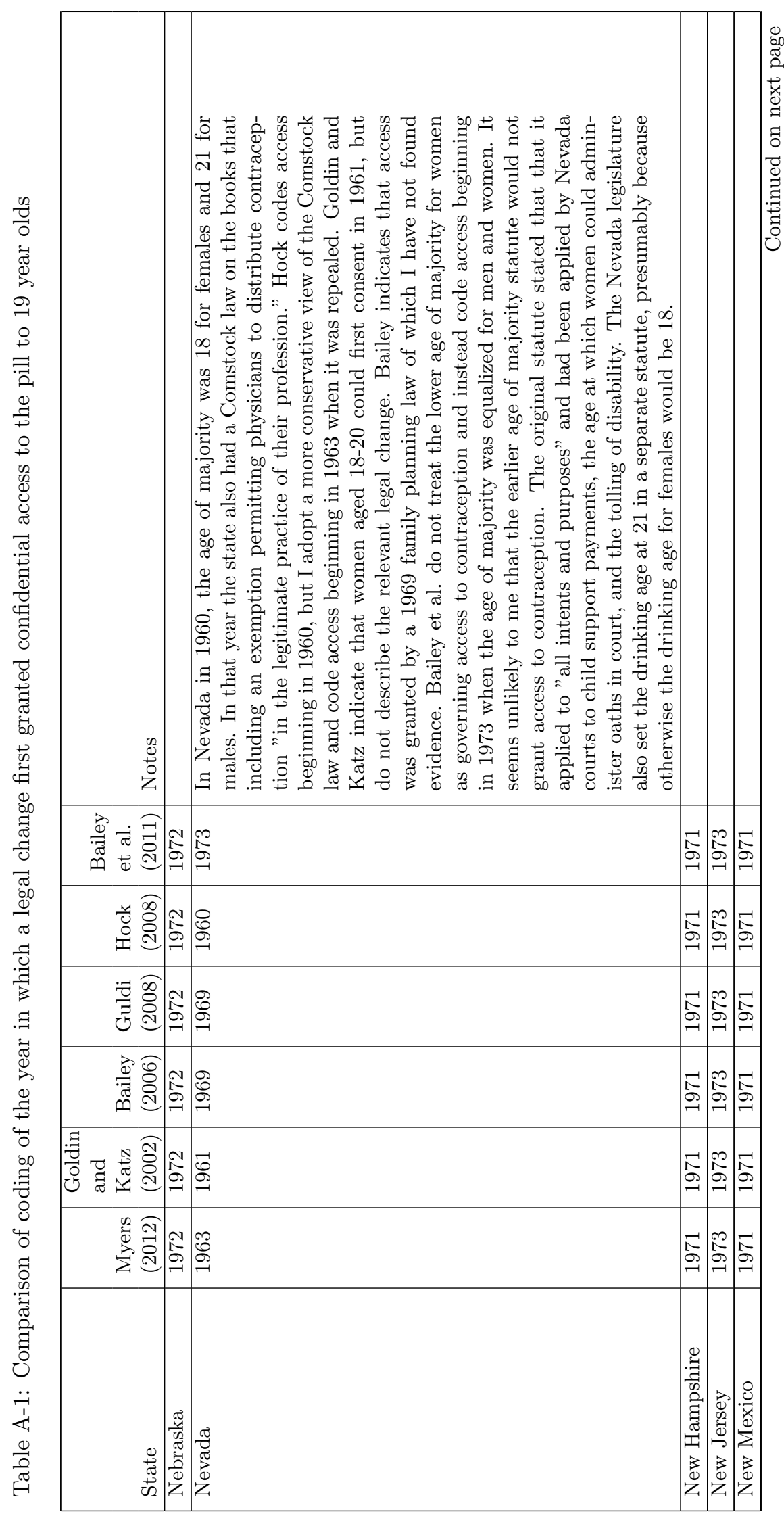

A-10 


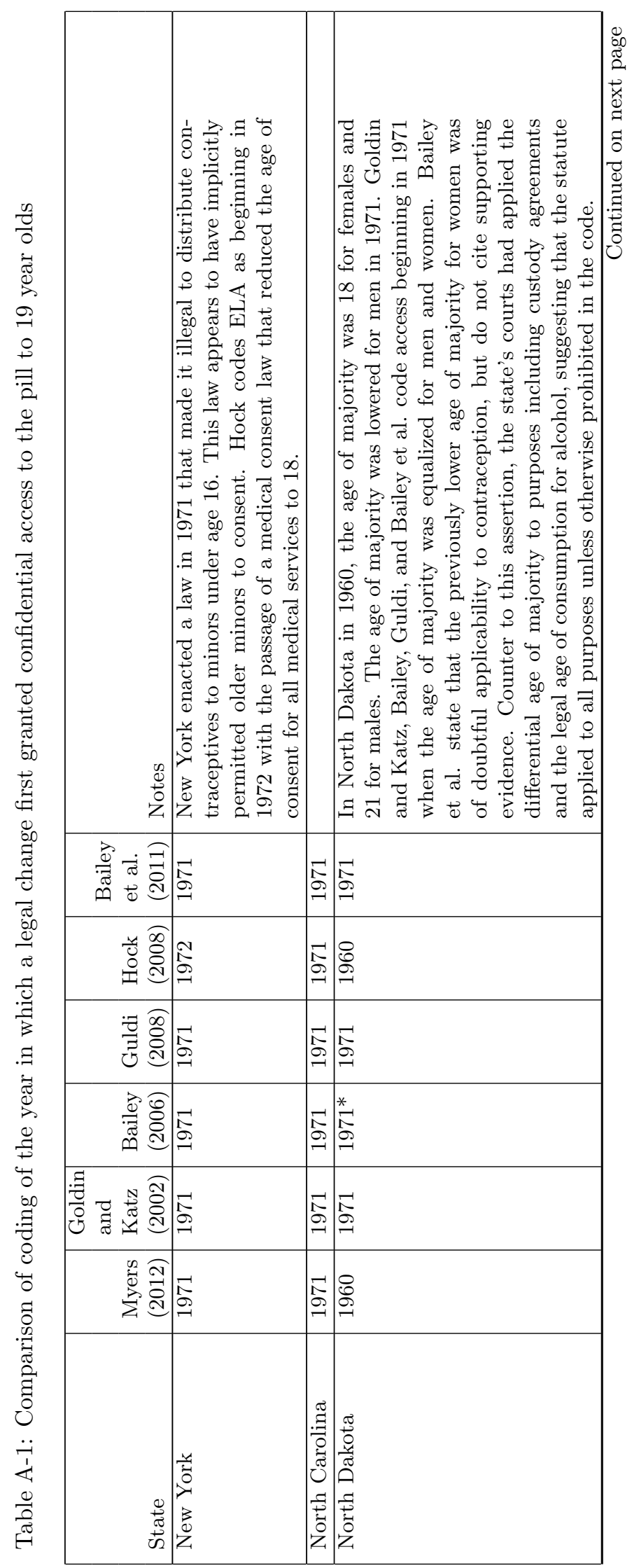

A-11 


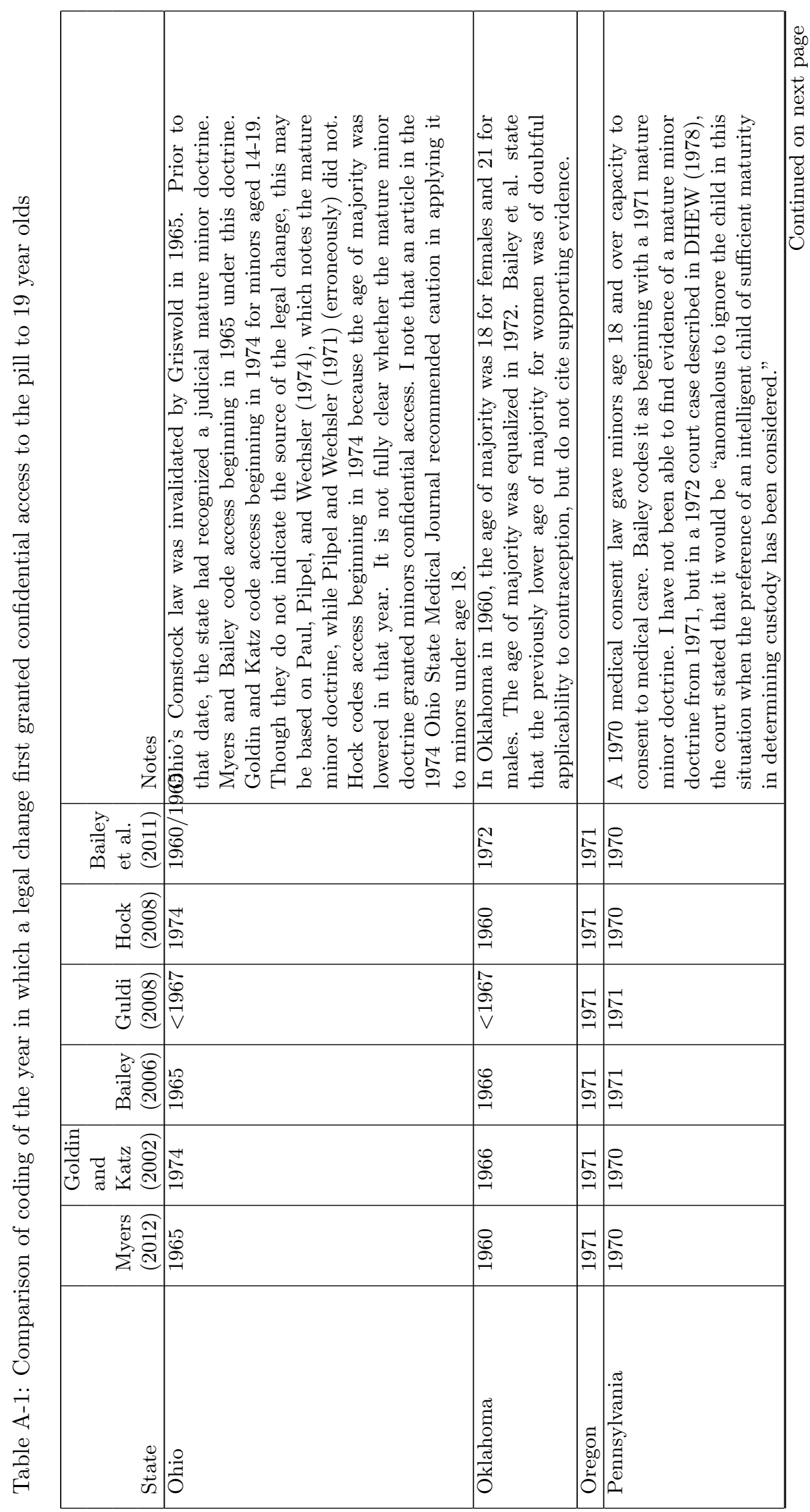

A-12 


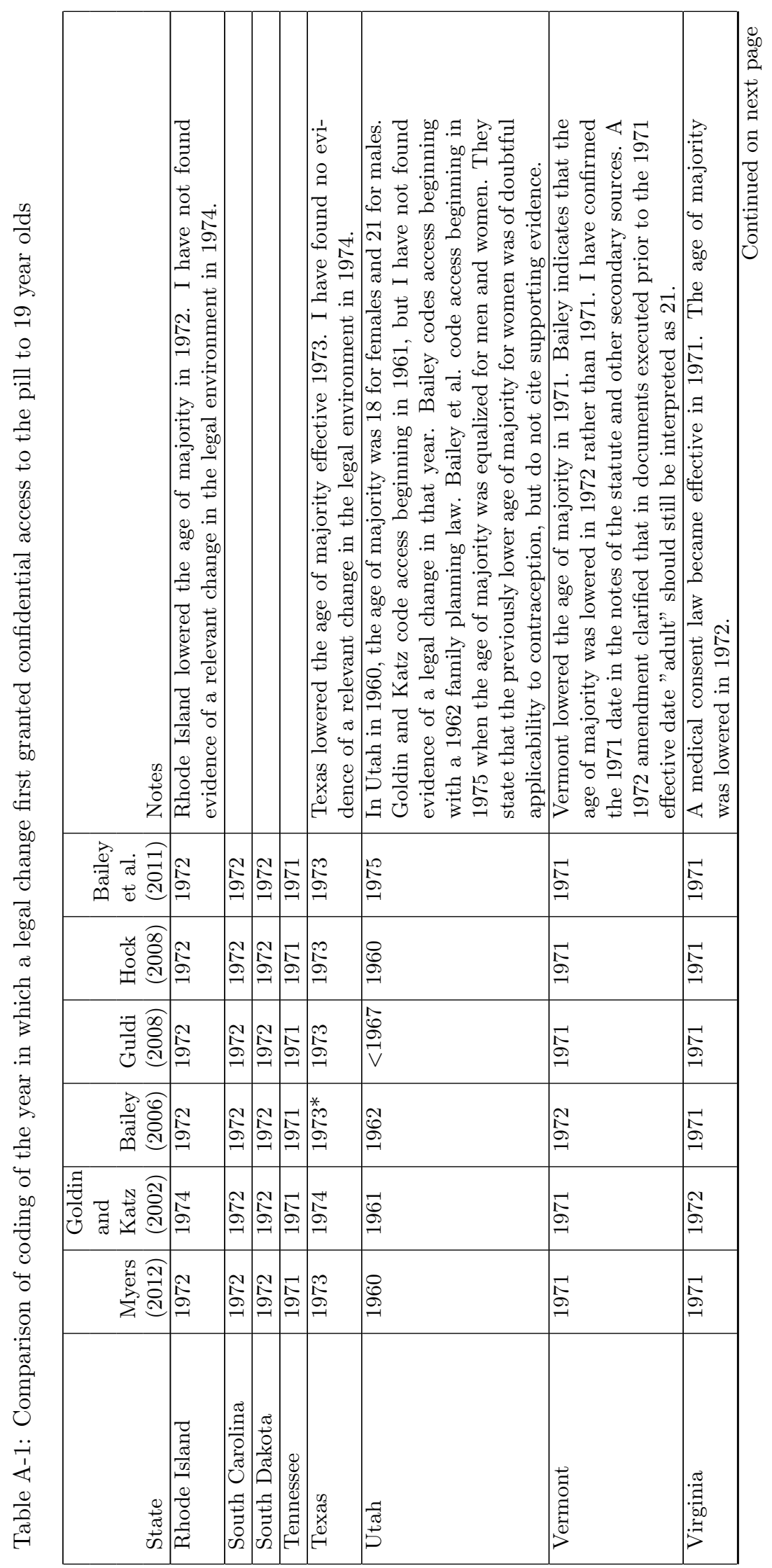

A-13 


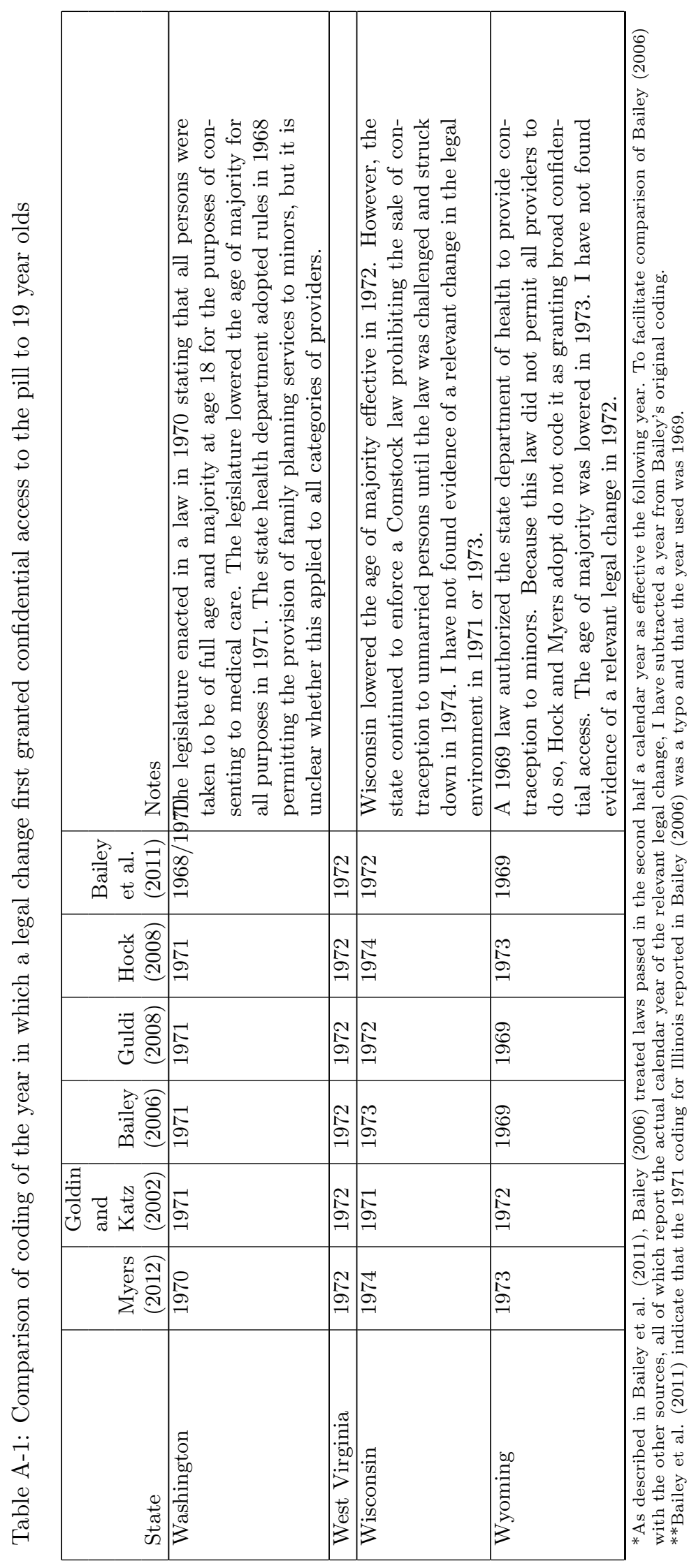

A-14 


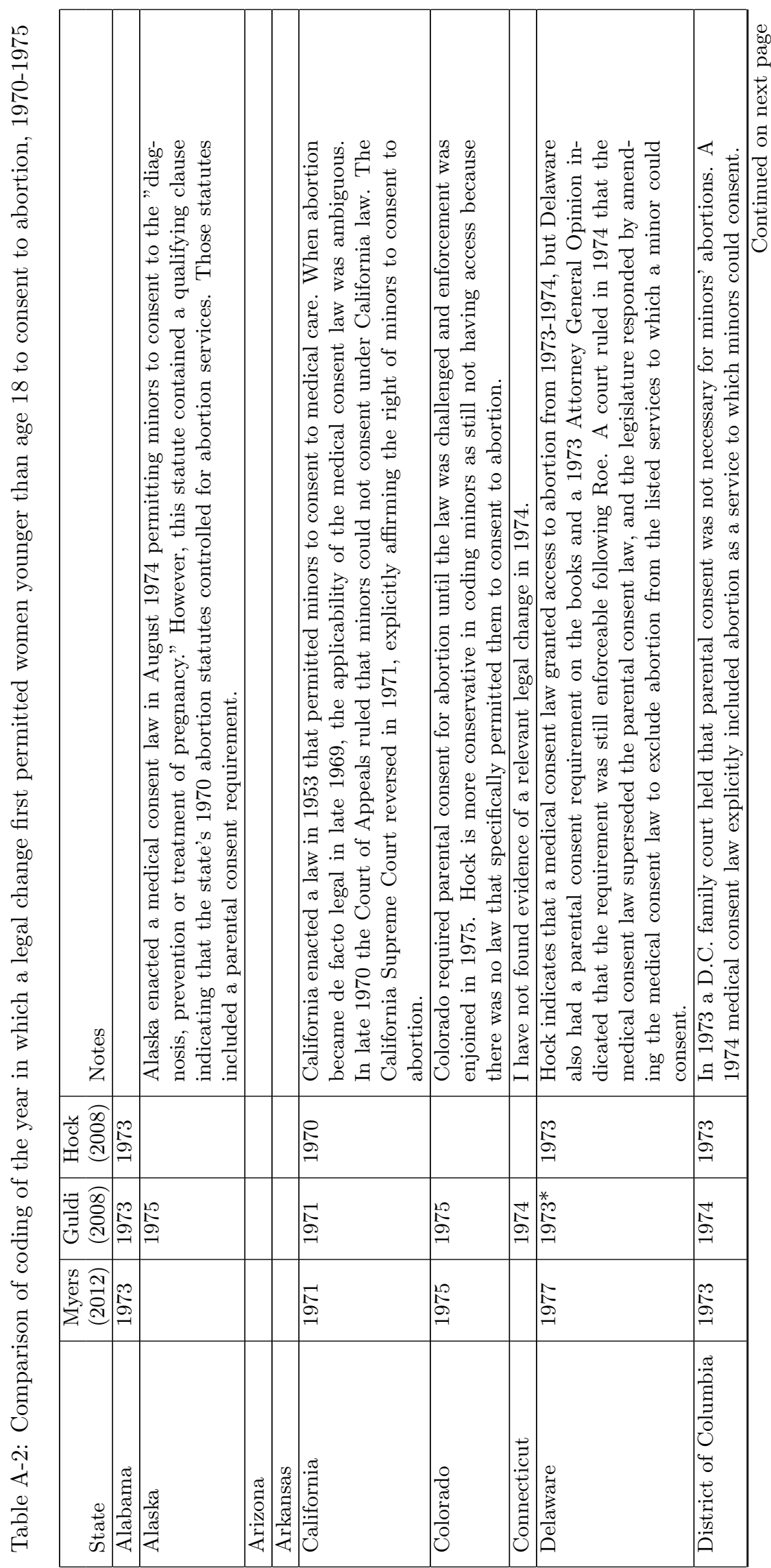




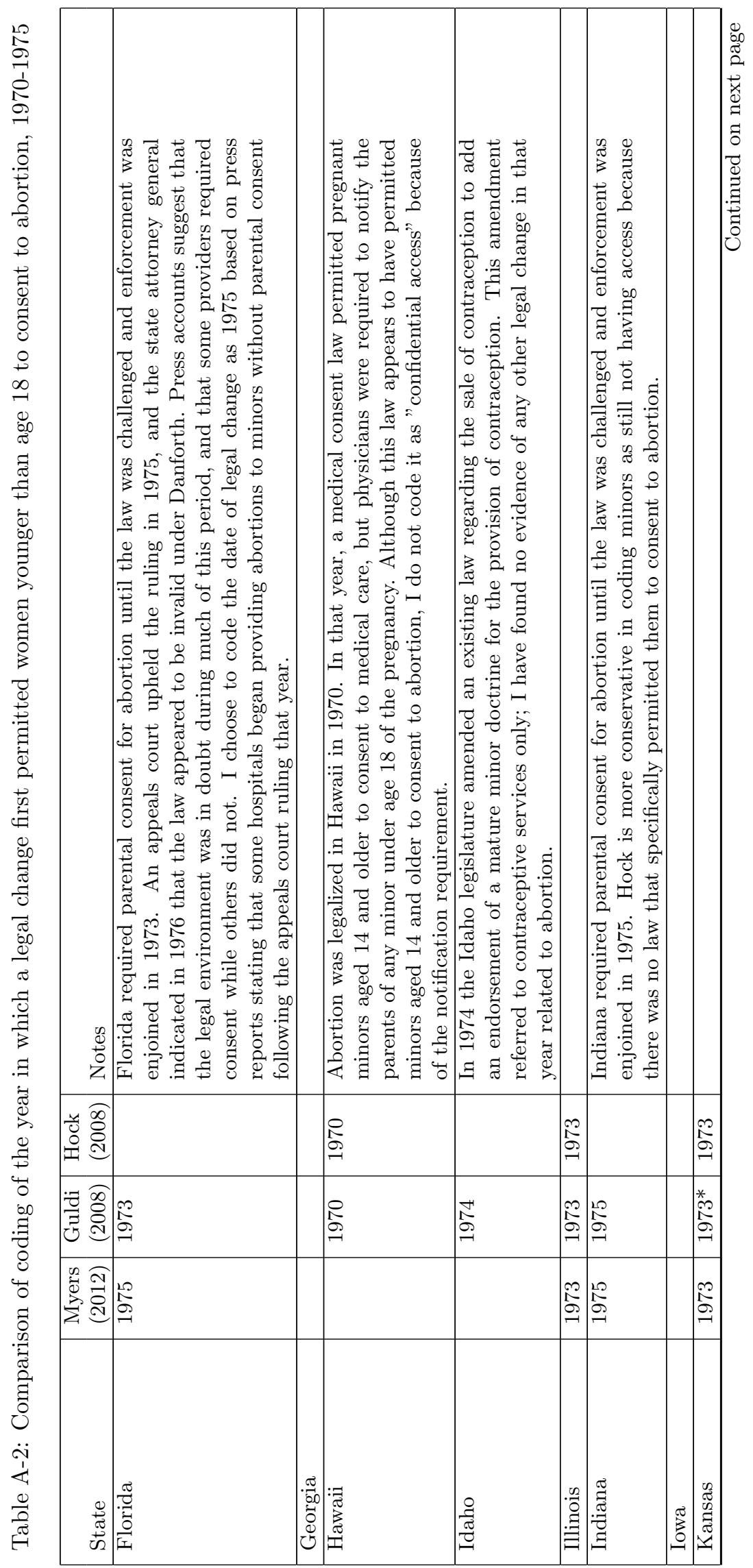




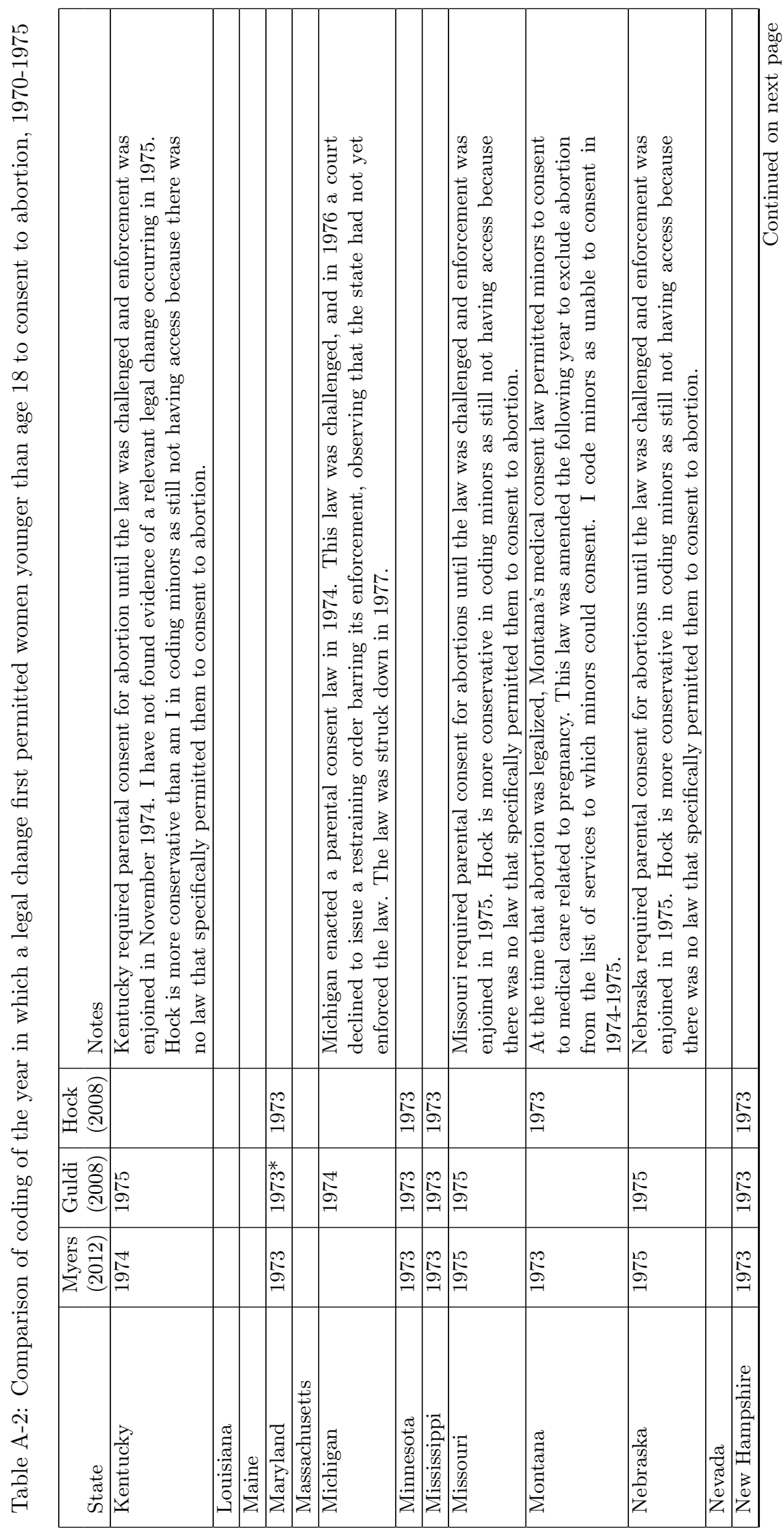




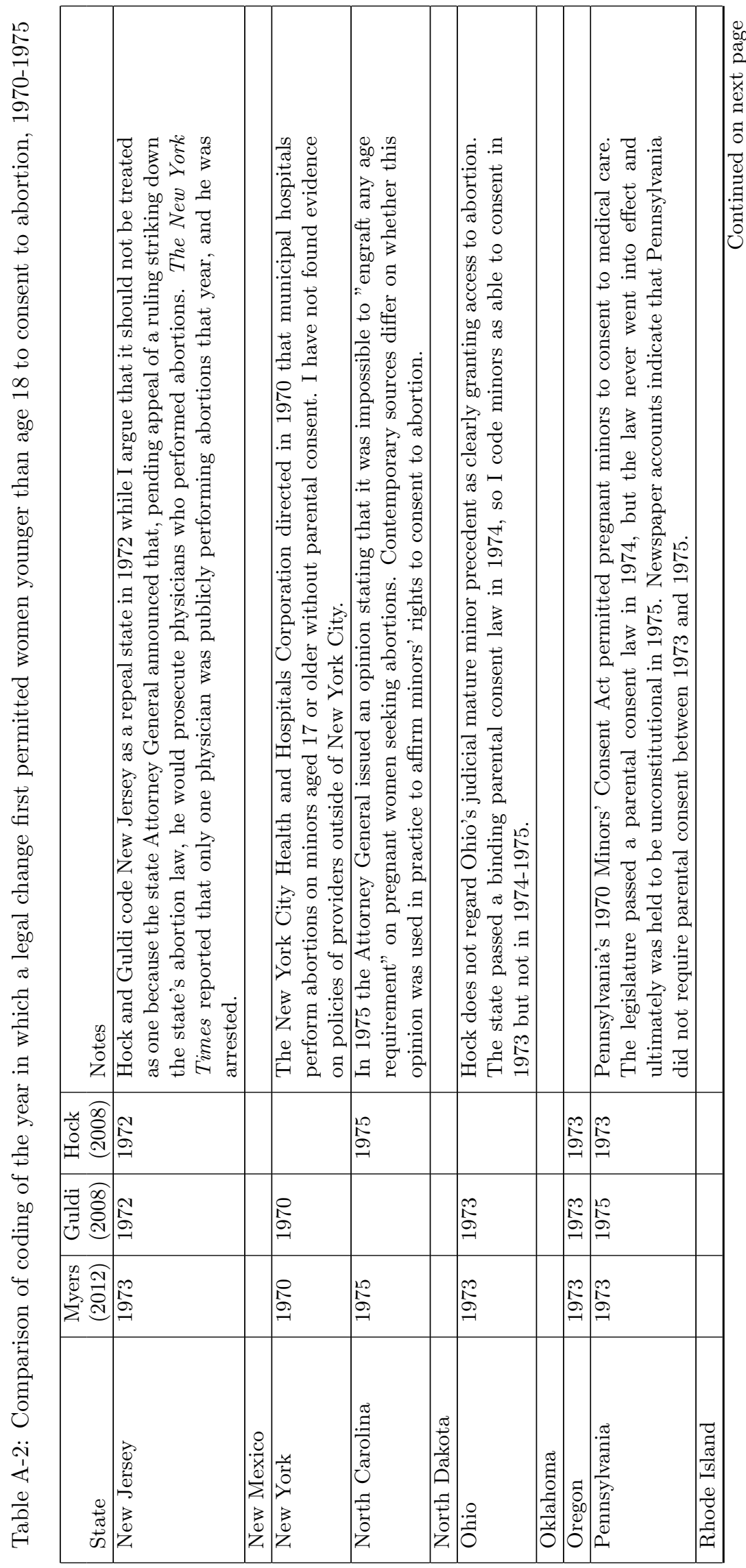




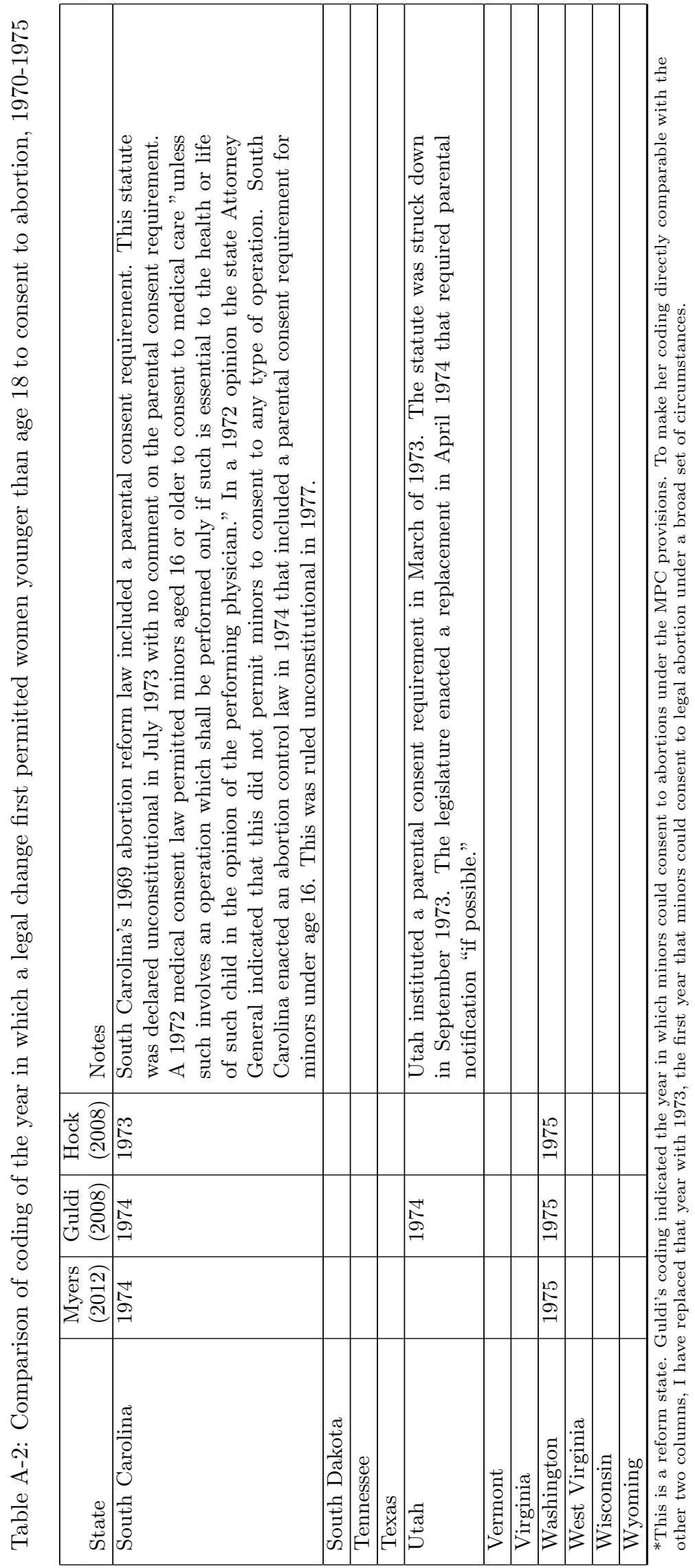


Appendix B: Replication and additional estimates based on Table 4 of Goldin and Katz (2002) 


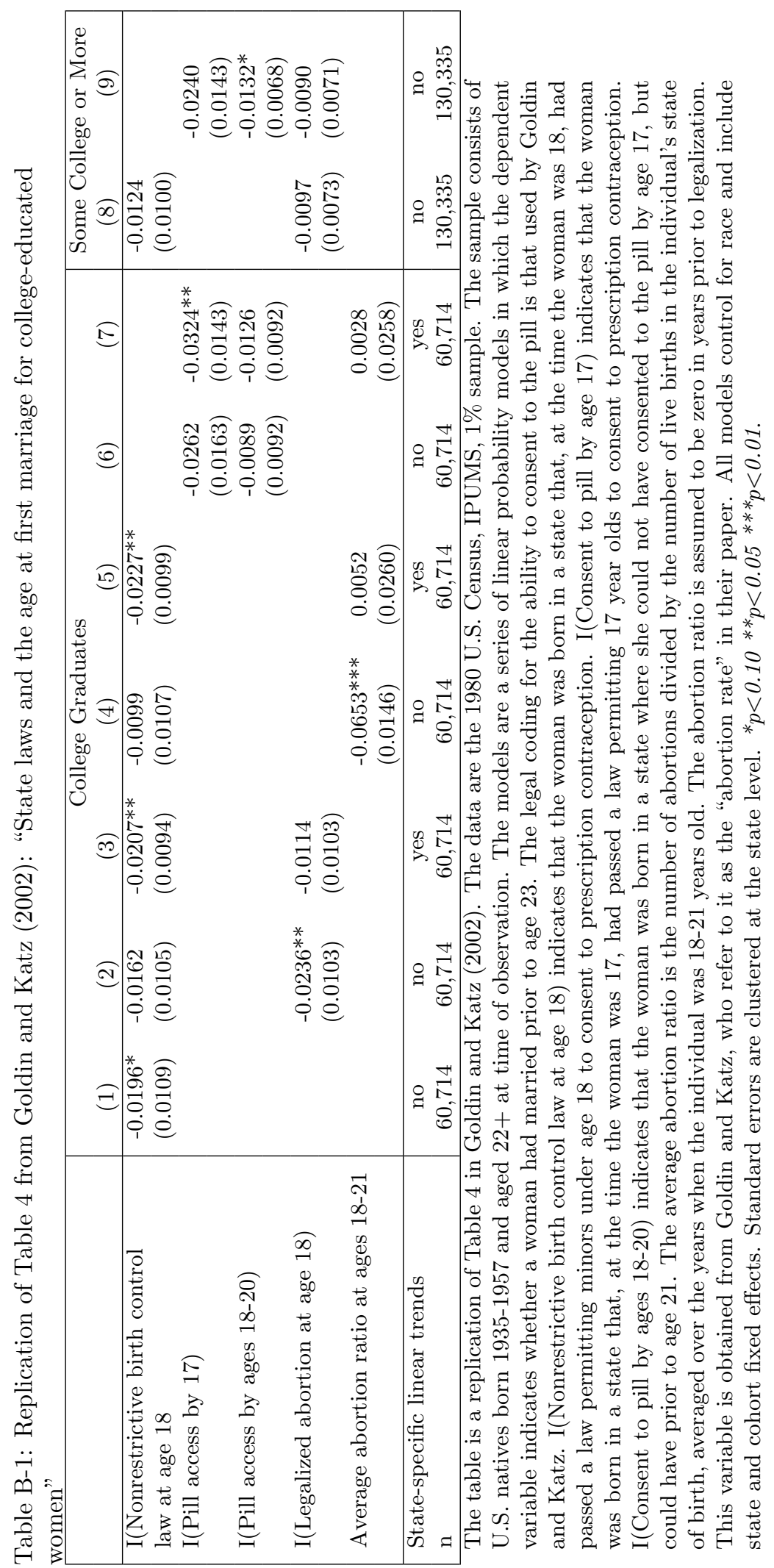

B-2 


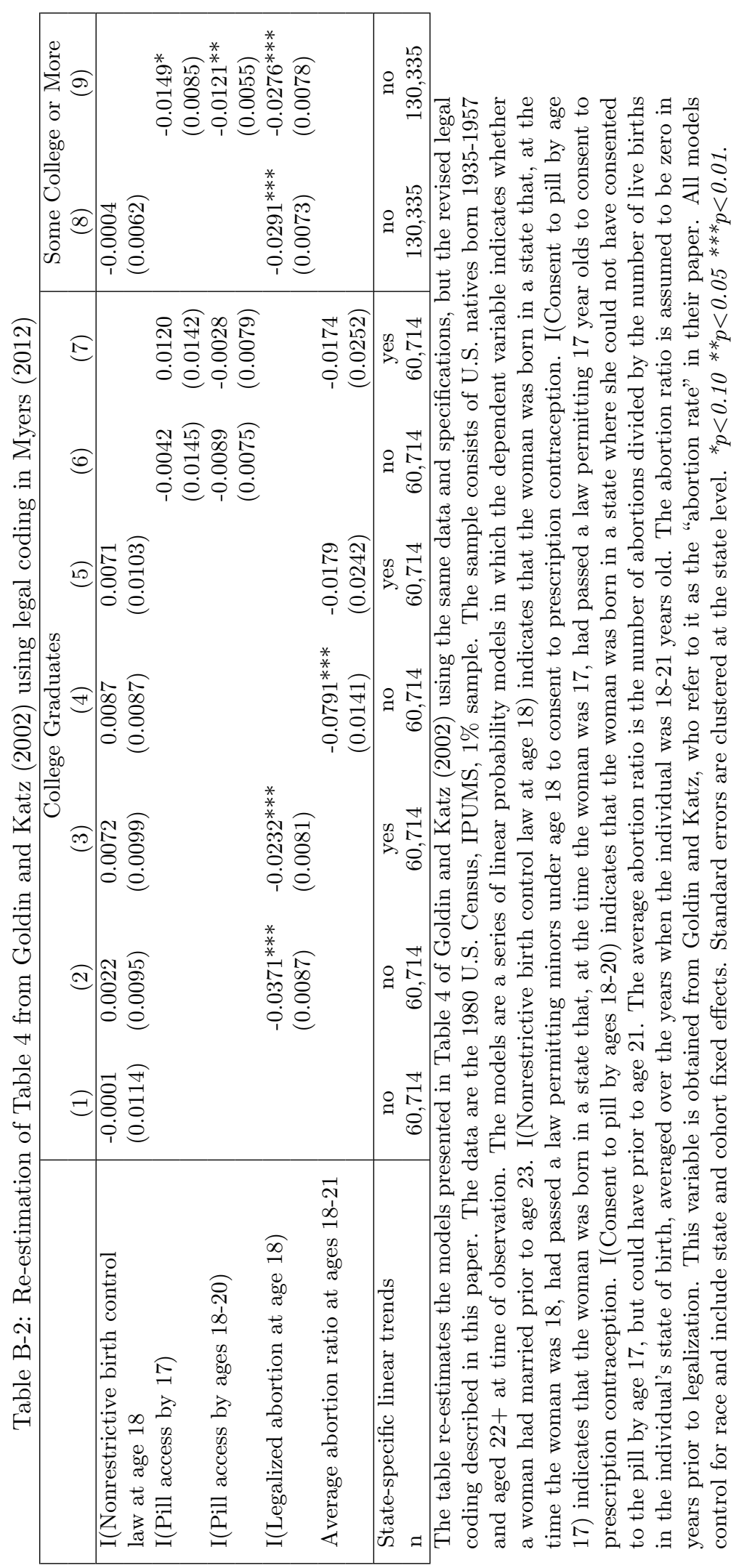

B-3 


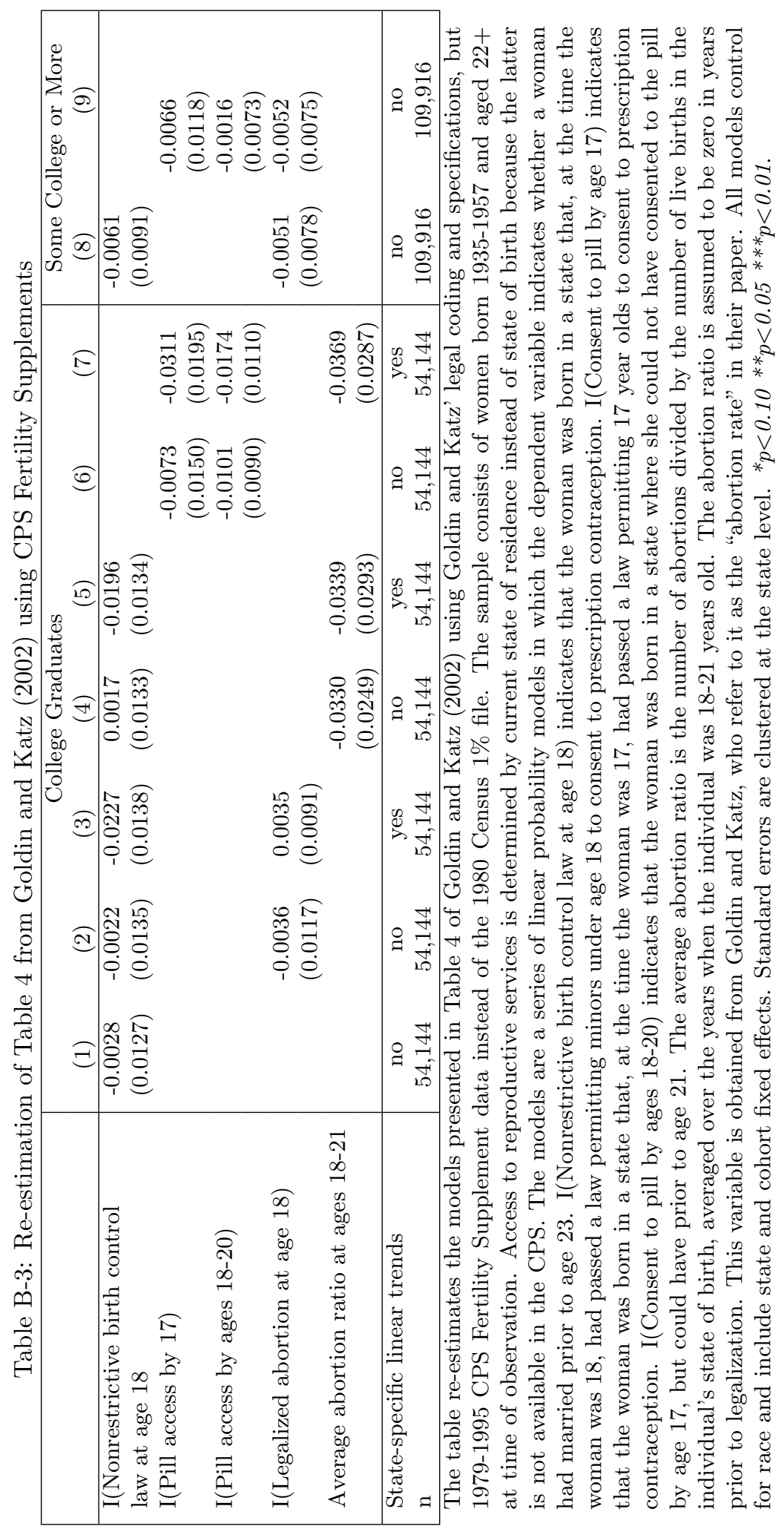

B-4 


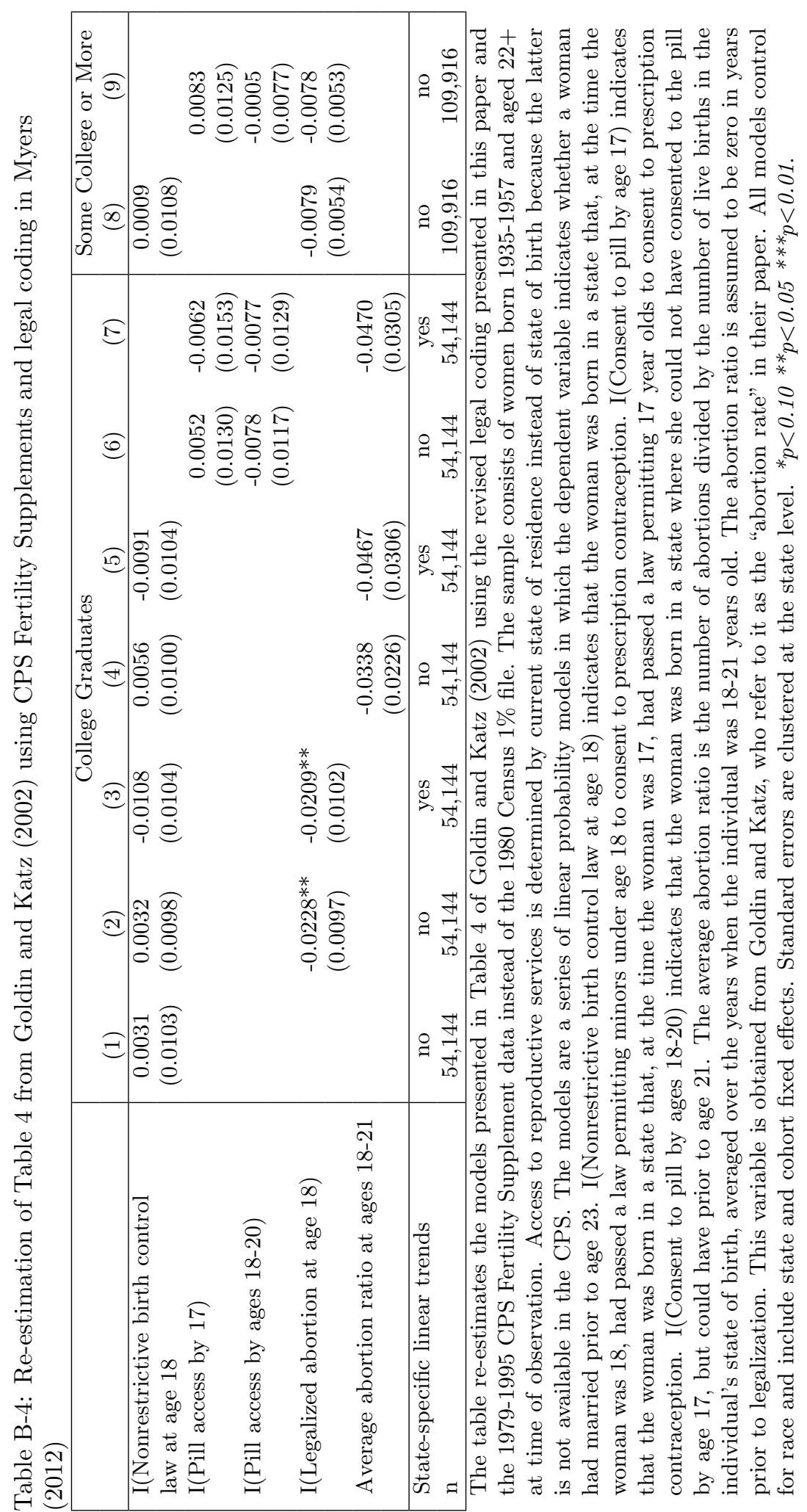

